TI 2019-002/VII

Tinbergen Institute Discussion Paper
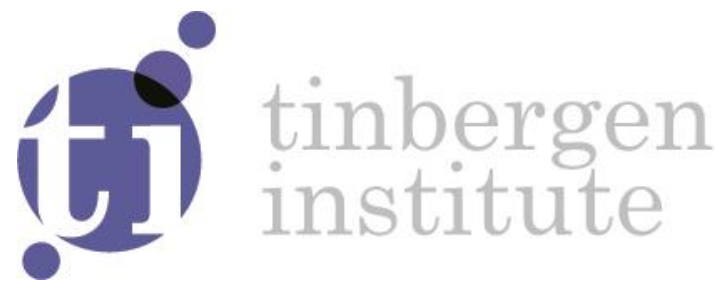

\title{
Banking Panics and the Lender of Last Resort in a Monetary Economy
}

Makoto (M.) Watanabe ${ }^{1}$

Tarishi Matsuoka²

${ }^{1}$ VU Amsterdam

2 Tokyo Metropolitan University 
Tinbergen Institute is the graduate school and research institute in economics of Erasmus University Rotterdam, the University of Amsterdam and VU University Amsterdam.

Contact: discussionpapers@tinbergen.nl

More TI discussion papers can be downloaded at http://www.tinbergen.nl

Tinbergen Institute has two locations:

Tinbergen Institute Amsterdam

Gustav Mahlerplein 117

1082 MS Amsterdam

The Netherlands

Tel.: +31(0)205984580

Tinbergen Institute Rotterdam

Burg. Oudlaan 50

3062 PA Rotterdam

The Netherlands

Tel.: +31(0)10408 8900 


\title{
Banking Panics and the Lender of Last Resort in a Monetary Economy*
}

\author{
Tarishi Matsuoka ${ }^{\dagger}$ Makoto Watanabe
}

January 4, 2019

\begin{abstract}
This paper studies the role of a lender of last resort (LLR) in a monetary model where a shortage of bank's monetary reserves (or a banking panic) occurs endogenously. We show that while a discount window policy introduced by the LLR is welfare improving, it reduces the banks' ex ante incentive to hold reserves, which increases the probability of a panic, and causes moral hazard in asset investments. We also examine the combined effect of other related policies such as a penalty in lending rate, liquidity requirements and constructive ambiguity.
\end{abstract}

Keywords: Monetary Equilibrium, Banking Panic, Moral Hazard, Lender of Last Resort

JEL Classification Number: E40

\footnotetext{
${ }^{*}$ We are grateful to Amy Sun, Aleksander Berentsen, Christopher Waller, David Andolfatto, Pedro GomisPorqueras, and Randy Wright for their comments and suggestions. We would also like to thank participants at the Search Theory Workshop in Nagoya, the Fifth Macro Marrakech Workshop in Marrakech, the Spring 2018 Midwest Macroeconomics Meetings in Madison, and the 2018 Summer Workshop on Money, Banking Payments and Finance in St. Louis. This work was supported by JSPS KAKENHI Grant Number 26780123 and a grant-in-aid from Zengin Foundation for Studies on Economics and Finance.

${ }^{\dagger}$ Tokyo Metropolitan University, JSPS Overseas Research Fellow, Address: Faculty of Urban Liberal Arts, Tokyo Metropolitan University, 1-1, Minami-Osawa, Hachioji, Tokyo, Japan 192-0397, Email: tarishi727@gmail.com

${ }^{\ddagger}$ VU Amsterdam, Tinbergen Institute, Address: Department of Economics, VU Amsterdam, De Boelelaan 1105, NL-1081 HV Amsterdam, The Netherlands, makoto.wtnb@gmail.com
} 


\section{Introduction}

The 2007-09 financial crisis has renewed interest in the role of the lender of last resort (LLR). After interbank markets stopped functioning properly, central banks in several developed countries conducted large-scale interventions beyond the traditional scope of open market operations. For example, the Federal Reserve began purchasing mortgage-backed securities and transferred emergency liquidity to troubled financial institutions. However, as Fischer (1999, p.86) stated, "While there is considerable agreement on the need for a domestic lender of last resort, some disagreements persist about what the lender of last resort should do."

In this paper, we study the economic role and consequence of the LLR. We develop a monetary model in which individual agents face idiosyncratic uncertainty about the payment method, that is, whether credit can be used in the decentralized market, and therefore banks are beneficial as liquidity insurance providers. Given aggregate uncertainty of money demand, banks are sometimes short of cash reserves and fail to satisfy their depositors' needs. In such a situation, which shall be referred to as a banking panic, there is room for emergency liquidity assistance by the LLR.

In our model, banks allocate their deposits between cash and long-term assets. In the benchmark without the LLR, banks invest all their deposits in cash reserves because nonmonetary assets have no use in the decentralized trade. In the presence of LLR, we consider discount window borrowing which is available only to those banks that hold a pledgeable longterm asset. This implies that with the LLR, long-term assets have a liquidity value during panics, and therefore banks invest a positive fraction of the deposits in it. This leads to a lower level of cash reserves and, thus, to a higher ex ante probability of banking panics relative to the benchmark without the LLR. Nevertheless, the introduction of the LLR improves welfare because cash and assets are substitutes during panics, and it mitigates losses associated with banking panics.

To examine asset choice, we consider two types of long-term assets: safe and risky assets. The safe asset is risk free. The risky asset yields a higher return if the gamble succeeds, but a lower return if not. We show that due to limited liability, which frees their payment 
responsibility in the case of default, banks can be induced to invest in the risky asset rather than the safe asset. Hence, the LLR can create moral hazard in asset investments, that is, banks take more financial risk in terms of long-term assets, resulting in a default on their discount window loans with a positive probability.

We examine two additional policies, liquidity requirements and constructive ambiguity, which are often implemented in practice together with discount window lending. We find that both of these policies can increase bank's cash reserves, which eventually lowers the probability of banking panics and reduces the bank's risk-taking incentives, with accompanying higher welfare costs. This result may suggest the limitations of the central bank's credible commitment on preventing banking panics and moral hazard, due to its welfare deteriorating nature, which in turn causes the time consistency problem.

Our paper points to the tension in public debate among economists and policy makers between the classical doctrine (or the Bagehot principle) versus the moral hazard problem. The former suggests that the LLR should give liquid loans to illiquid but solvent banks at a high interest rate (or a "penalty" rate) against their good collateral (Thornton, 1802; Bagehot, 1873), while the latter concerns high financial risks taken by illiquid banks. This is one of the central issues of the LLR policy debates. The conventional view is that a high loan rate on the discount window prevents not only borrowing of unnecessary amounts of liquidity but also taking excessive risks. For example, Solow (1982) states that "the penalty rate is a way of reducing moral hazard (p.247)," and Fischer (1999) comments that "the lender of last resort should seek to limit moral hazard by imposing costs on those who have made mistakes. Lending at a penalty rate is one way to impose such costs (p.93)." Our results do not concur this view for several reasons. First, we show that if the expected return on the risky asset is sufficiently high, changing the lending rate has no influence on asset choice. Second, the penalty rate could reduce welfare if another policy such as liquidity requirements or constructive ambiguity is combined. Finally, things are not so simple once the banks' asset choice is taken into account. For instance, a higher lending rate can lower the probability of banking panics but leads to a switch in banks' investment from the safe asset to the risky asset, leading to possible 
defaults. Hence, a penalty rate aimed at reducing the probability of banking panic can cause an adverse effect on risk-taking investments and defaults. The description of breadth (banking panics) and depth (defaults) of financial fragility is possible in the presence of the LLR only in a framework where investments in the risky asset are allowed. To the best of our knowledge, our paper is the first to point out this possibility.

\subsection{Related Literature}

The LLR policy has a long history; its concept was elaborated in the 19th century by Thornton (1802) and Bagehot (1873). The classical doctrine has been criticized on two grounds. First, Goodfriend and King (1988), Kaufman (1991), and Schwartz (1992) argue that with efficient interbank markets, central banks should not lend to individual banks, but instead provide liquidity via open market operations. However, others argue that interbank markets may fail to allocate liquidity efficiently due to asymmetric information (Flannery, 1996; Freixas and Jorge, 2007; Heider, Hoerova, and Holthausen, 2015), free-riding (Bhattacharya and Gale, 1987), coordination failures (Freixas, Parigi, and Rochet, 2000), incomplete network (Allen and Gale, 2000), incomplete contracts (Allen, Carletti, and Gale, 2009), or market power (Acharya, Gromb, and Yorulmazer, 2010), which can justify the role of the LLR. In this paper, we do not model interbank markets explicitly, but consider a situation where a shortage of liquidity in a whole banking system occurs endogenously due to aggregate demand shocks that market capacity cannot satisfy.

Second, Goodhart $(1987,1999)$ argue that there is no clear-cut distinction between illiquidity and insolvency during a crisis and banks that require the LLR assistance are already under suspicions of insolvency. See also Solow (1982) and Schwartz (1992) for some more related issues. Our model captures Goodhart's emphasis well because in our setup the central bank must lend money to illiquid banks without knowing whether they would be insolvent.

In practice, central banks in many countries have expanded their LLR function beyond the classical Bagehot rule since the 1970s. ${ }^{1}$ For example, Bordo (2014) points out that since the

\footnotetext{
${ }^{1}$ According to Bordo (1990), major central banks in European countries generally followed the classical
} 
bailout of Franklin National Bank in 1974, the Fed's LLR policy has adopted the too-big-tofail doctrine to prevent systemic risk and contagion irrespective of the classical doctrine. In addition, Giannini (1999) claims that most LLR policies adopted a non-penalty rate or even a subsidized rate without having stated it clearly in advance. There is no doubt that the moral hazard associated with these LLR policies is a serious concern. However, we do not have any theory taking into account monetary liquidity supports and moral hazard. We propose a new theory to fill this gap.

Our study is related to the following three strands of literature. The first strand focuses on financial crises and the role of the LLR in a standard non-monetary banking model, for example, Allen and Gale (1998), Freixas, Parigi, and Rochet (2000), Rochet and Vives (2004), Repullo (2005), Martin (2006, 2009), Allen, Carletti, and Gale (2009), and Acharya, Gromb, and Yorulmazer (2010). Some of them regard LLR policies as real tax-transfer schemes without monetary considerations, while others consider monetary transfers but while treating nominal assets as an exogenous restriction. In contrast, our approach is to take monetary factors as the main driving force, because we believe that banking panics should represent a widespread attempt by the public to convert their deposits into currency and a suspension of convertibility (Calomiris and Gorton, 1991; Champ, Smith, and Williamson, 1996), and that the abilities of creating high-powered money and distributing it quickly authorize a central bank to act as a lender of last resort (Schwartz, 2002).

The second strand examines monetary factors of the LLR in an overlapping-generations model with random relocation along the lines of Champ, Smith, and Williamson (1996) and Smith (2002). See also Antinolfi, Huybens and Keister (2001), Antinolfi and Keister (2006) and Matsuoka (2012). Unlike our model, these models do not consider risky financial technologies and moral hazard associated with the LLR. We offer a new and simple approach to make the moral hazard problem, which is potentially very complicated, tractable.

The third strand considers banking with a New Monetarist approach along the lines of

doctrine between 1870 and 1970. In contrast, the Bank of Japan provided liquidity support to large illiquid and insolvent banks at a non-penalty rate based on the too-big-to fail doctrine in response to the financial panic of 1927 (Yokoyama, 2018). 
Lagos and Wright (2005) and Rocheteau and Wright (2005). This strand includes Andolfatto, Berentsen, and Martin (2017), Berentsen, Camera, and Waller (2007), Ferraris and Watanabe (2008, 2011), Bencivenga and Camera (2011), Williamson (2012, 2016), Gu, Mattesini, and Wright (2013), and Matsuoka and Watanabe (2017). None of them considers the economic role and consequences of the LLR and other related policies.

The rest of the paper is organized as follows. Section 2 describes the basic environment. Section 3 analyzes the case without the LLR. Section 4 analyzes the case with the LLR and explores the condition of moral hazard. Section 5 considers extensions. Section 6 concludes. All mathematical proofs are provided in the Appendix.

\section{Environment}

The model builds on a version of Lagos and Wright (2005). Time is discrete and continues forever. Each period is divided into two subperiods: day and night. A market is open in each subperiod. There are two types of $[0,1]$ continuum of infinitely-lived agents. Agents of the same type are homogeneous. One type of agents, called sellers, have the production technology during the day, which allows them to produce perishable and divisible goods, referred to as special goods. The other type of agents, called buyers, do not have the production technology during the day but can consume the special goods. Other divisible goods, referred to as general goods, are produced and consumed during the night. There is also an intrinsically worthless good, which is perfectly divisible and storable, called fiat money. Agents discount future payoffs at a rate $\beta \in(0,1)$ across periods, but there is no discounting between the two subperiods.

The instantaneous utility functions for buyers and sellers are given by $u\left(q^{b}\right)+U(x)-h$ and $-q^{s}+U(x)-h$, respectively, where $q^{b}$ represents the amount of special goods that the buyer consumes, $q^{s}$ is the amount of special goods that the seller produces, $h$ is the nighttime hours of work, and marginal production costs are constant, normalized to one. The utility function $u(q)$ is strictly increasing, strictly concave, and twice continuously differentiable with $u(0)=0, u^{\prime}(0)=\infty, u^{\prime}(\infty)=0$, and with the property that there exists some $\hat{q}>0$ such that 
$u(\hat{q})=\hat{q}$. For analytical tractability, we assume $\xi \equiv-\frac{q u^{\prime \prime}(q)}{u^{\prime}(q)}$ is a positive constant. The utility function of general goods, $U(x)$, is also strictly increasing, concave, and twice continuously differentiable. We normalize $U\left(x^{*}\right)-x^{*}=0$, where $x^{*}$ solves $U^{\prime}\left(x^{*}\right)=1$.

During the day, buyers and sellers can trade special goods in decentralized markets (DM), which involves bilateral random matching. Just like in Sanches and Williamson (2010) and Williamson (2012) (see also Section 5 of Williamson and Wright, 2010), we assume that in a DM, there are a fraction $\alpha \in(0,1)$ of sellers who are engaged in a non-monitored exchange and a fraction $1-\alpha$ of sellers who are engaged in a monitored exchange. At the beginning of the day, sellers meet with their counterparts and buyers learn whether they will trade with sellers in non-monitored or monitored meetings. In the non-monitored exchanges, exchanges are anonymous and trading histories are private knowledge, and thus, given the random meeting, sellers must receive money for immediate compensation of their products. In contrast, there is a record-keeping technology in the monitored exchange, and perfect commitment is possible so that buyers can promise credibly that they will make a payment to sellers later during the night. That individual buyers face randomness in different requirements of the medium of exchange, plays the role of a "liquidity preference shock." This is similar in the spirit to Diamond and Dybvig (1983) to motivate the banks' risk sharing role. In any meeting, we assume for simplicity that buyers make a take-it-or-leave-it offer to sellers.

The fraction $\alpha$ of monitored/non-monitored meetings is a random variable. It is publicly observable and identically distributed over time. Let $F=F(\alpha)$ represent the distribution function, which is assumed to be continuous, differentiable, and strictly increasing, and $f=$ $f(\alpha)>0$ is the associated density function. As mentioned earlier, this randomness will play a key role in our model.

One can imagine several interpretations of the stochastic fluctuations of $\alpha$. First, it is typically thought of as a seasonal variation in the demand for money. Historically, large seasonal pressures, mostly in the spring planting season and fall crop moving season, have caused banking panics in agricultural economies (e.g., Sprague, 1910; Miron, 1986; Calomiris and Gorton, 1991). Second, small changes in the cost of information acquisition about counter- 
party or asset quality used as collateral in an imperfect credit system would have large effects on credit transactions (Lester, Postlewaite, and Wright, 2012). Finally, unexpected events such as large-scale natural disasters, blackouts, and September 11, 2001, would damage social communication tools necessary for credit transactions and suddenly increase the aggregate demand for money. As these seem potentially relevant, we are agnostic about the exact nature of stochastic fluctuations.

During the night, general goods are traded in the centralized market (CM), which is Walrasian. Buyers have access to a storage technology which allows them to hold long-term assets across periods. We consider two types of assets. A safe asset transforms one unit of the general good into $R>1$ units of the general good in the next period. We consider the case $\beta R<1$ to avoid an explosive solution or indeterminacy. A risky asset yields a stochastic return, $\lambda R$, with probability $\eta$, or zero with probability $1-\eta$, where $\lambda>1$ and $\eta \lambda \leq 1 .^{2}$ Thus, risk-averse and risk-neutral agents strictly prefer the safe asset to the risky asset, and moral hazard is said to occur if the risky asset is selected. In addition, we assume that only a fraction $R$ of the successful return on the risky asset, $\lambda R$, is observable and verifiable, implying that only this fraction can be used as collateral when needed for discount window borrowing (see below). The remaining fraction $(\lambda-1) R$ of the return is neither observable nor verifiable by outsiders (e.g., the central bank). This unobservable extra return can be interpreted as "private benefit" as in a standard moral hazard model (e.g., Holmstrom and Tirole, 1997). The asymmetric information implies that outsiders cannot observe whether the bank chooses the safe or risky asset until the risky asset produces nothing. The term "investment in the risky assets" can be interpreted broadly to include low efforts for screening projects, monitoring projects, or management of financial risks. Typically, these efforts are costly and not observable by outsiders, implying that there is private benefit from shirking.

In a CM, buyers form private banks. A bank offers a contract to each of its depositors which stipulates a repayment plan as specified below. Depositors are buyers who deposit general goods in the CM and may need cash in the following DM. The bank stocks $m$ money

\footnotetext{
${ }^{2}$ A similar assumption is made in Cooper and Ross (2002) and Martin (2006).
} 
(or $z \equiv \phi_{-1} m$ real cash balances) and $k$ safe and $l$ risky assets in the CM. Any credit contracts in the DM are settled in the CM of the same period. The timing of events is illustrated in Figure 1.

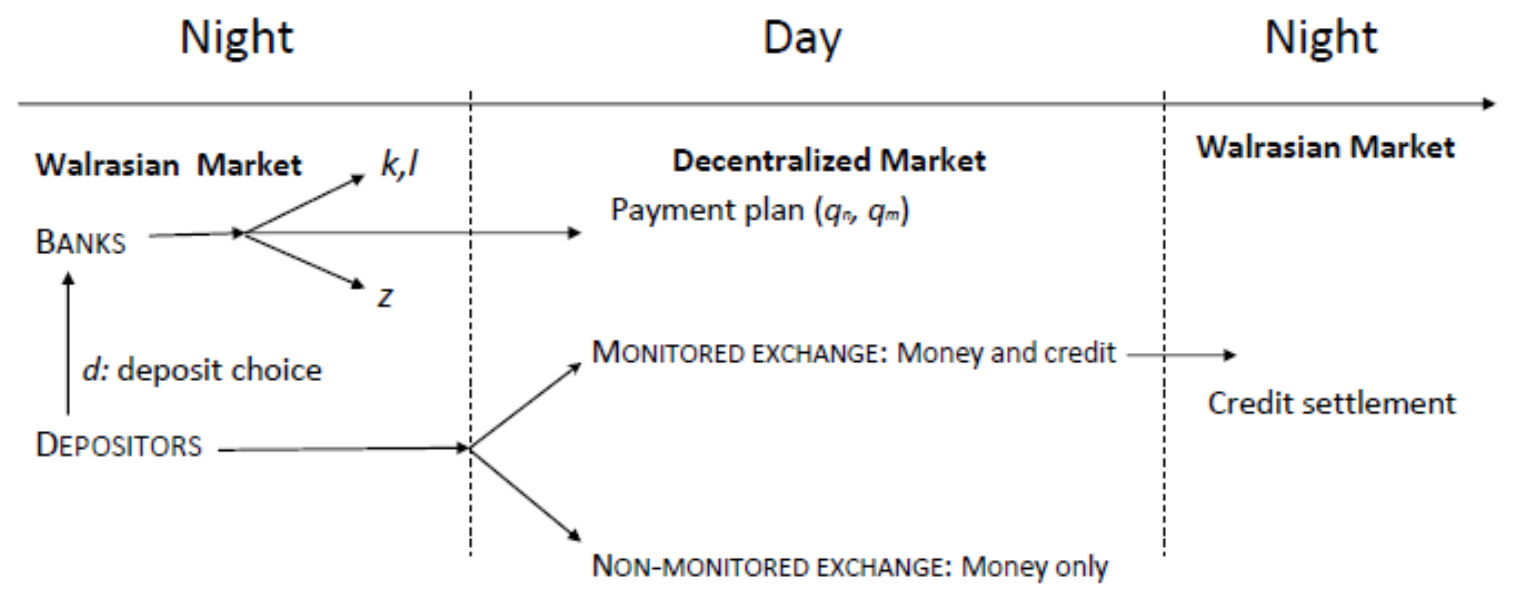

Fig 1: Timing of events

The stock of money available in a period is denoted by $M$. It grows (or shrinks) at a constant rate $\pi$, that is, $M_{+}=\pi M$, through injection to (or withdrawing it from) buyers in a lump-sum manner in the CM, where the subscript "+" stands for the next period. The price of money is denoted by $\phi$ in terms of general goods. Then, we consider that the rate of return on money is dominated by the returns on both safe and risky assets:

$$
\frac{\phi_{+}}{\phi}<\eta \lambda R(=\min \{\eta \lambda R, R\})
$$

Finally, the money market clears in each period so that the return on money must be equal to the inverse of the inflation rate, $\frac{\phi_{+}}{\phi}=\frac{1}{\pi}$.

The first-best solution in our economy is straightforward. The socially optimal level of long-term assets, both safe and risky, equals 0 since $\beta \max \{\eta \lambda R, R\}=\beta R<1$. The socially optimal levels of consumption equal $q^{*} \equiv u^{-1 \prime}(1)$, that is, the marginal utility of special goods consumption $\left(=u^{\prime}\left(q^{*}\right)\right)$ is equal to the marginal cost $(=1)$, and $x^{*} \equiv U^{-1 \prime}(1)$, that is, the marginal utility of general goods consumption $\left(=U^{\prime}\left(x^{*}\right)\right)$ is equal to the marginal cost $(=1)$. 


\section{Monetary equilibrium without LLR}

We first derive a monetary equilibrium without an LLR. Given that perfect credit is available, a buyer in a monitored exchange can purchase and consume any quantity they wish to irrespective of their daytime money holdings, since the payment can be made later at night. Hence, in each period, a buyer in the monitored exchange consumes the first best quantity, that is, $q^{m}=q^{*}$. As the buyers in a monitored meeting do not need cash during the day, banks do not allocate cash to these buyers.

Banks' repayment schedules should determine how much money to allocate to each nonmonitored buyer. At the beginning of a day, before buyers find out the type of their meeting, banks choose a payment schedule given their holdings of cash, $m$, selected in the previous $\mathrm{CM}$ (see below). The payment can be contingent on the realized aggregate state. We assume competitive banks with free entry, so that each maximizes the expected value of its representative depositor (i.e., buyer). Denote by $q^{n}=q^{n}(\alpha)$ the consumption of a non-monitored buyer, and by $\theta=\theta(\alpha)$ the fraction of its cash reserves that a bank pays out to non-monitored buyers. Without loss of generality, the remaining cash reserves are distributed uniformly among monitored buyers after the day market closes. For each realized value $\alpha \in(0,1)$, a bank's maximization problem in the DM can be written as:

$$
\max _{\theta \in[0,1]} \alpha u\left(q^{n}\right)+(1-\theta) \frac{z}{\pi}
$$

subject to

$$
\alpha q^{n}=\frac{\theta z}{\pi}
$$

where $z \equiv \phi_{-1} m$ is the real reserve balances. The first term in the objective function represents the daytime utility of non-monitored buyers, who need cash for the daytime trade, and the second term, the nighttime real value of the remaining cash reserves. The constraint states that each individual non-monitored buyer receives $\frac{\theta m}{\alpha}$ units of cash from the bank and, given take-it-or-leave-it offers, exchanges it with the matched seller for $\frac{\theta m \phi}{\alpha}=\frac{\theta z}{\pi \alpha}$ units of special goods. 
The first order condition is

$$
\frac{z}{\pi}\left\{u^{\prime}\left(q^{n}\right)-1\right\} \geq 0 \quad(=\text { if } \theta<1)
$$

This condition shows that two situations are possible in a monetary equilibrium (i.e., with $z>0)$. The first condition, $\theta<1$, implies $q^{n}=q^{m}\left(=q^{*}=u^{-1 \prime}(1)\right)$, that is, consumption smoothing. The other, $\theta=1$, implies that the bank exhausts all its cash reserves and fails to achieve consumption smoothing, that is, $q^{n}<q^{m}$. We refer to such an event as a banking panic. This definition captures the situation where a significant number of depositors suddenly demand to redeem bank debt for cash, leading to a shortage of the overall amount of reserves in the banking system and a suspension of convertibility. It follows:

Lemma 1 (Banks' Optimal Payment Plan) Given cash reserves $z>0$, the optimal payment plan of banks is described by $q^{m}=q^{*}$ and

$$
q^{n}(\alpha)= \begin{cases}q^{*} & \text { if } 0<\alpha<\alpha^{*} \\ \frac{z}{\alpha \pi} & \text { if } \alpha^{*} \leq \alpha<1\end{cases}
$$

where $\alpha^{*} \equiv \frac{z}{\pi q^{*}}>0$, and

$$
\theta(\alpha)= \begin{cases}\frac{\alpha}{\alpha^{*}} & \text { if } 0<\alpha<\alpha^{*} \\ 1 & \text { if } \alpha^{*} \leq \alpha<1 .\end{cases}
$$

The lemma shows that the occurrence of a banking panic can be stated in terms of realized values of $\alpha$. For low values of $\alpha<\alpha^{*}$, the realized aggregate demand for money is relatively low, so that banks' cash reserves are sufficient to cover the needs of the non-monitored buyers, leading to $q^{n}=q^{*}$ and $\theta<1$. For high values of $\alpha \geq \alpha^{*}$, the realized aggregate demand for money is relatively high and, thus, banks' cash reserves are not enough to cover the needs of non-monitored buyers, leading to $q^{n} \leq q^{*}$ and $\theta=1$. This results in a banking panic. Figure 2 illustrates this lemma. 


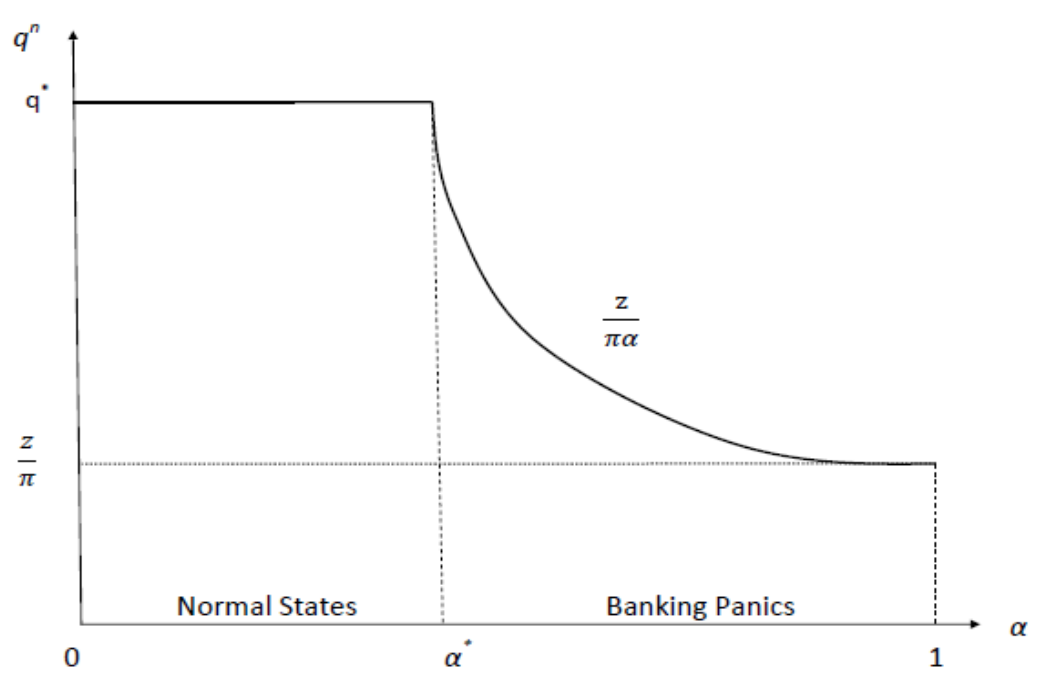

Fig 2: Consumption in a non-monitored exchange

Since $q^{n} \leq q^{m}$ for any $\alpha$, the allocation is clearly incentive-compatible or truth-telling, which states that monitored buyers weakly prefer their own consumption to that of nonmonitored buyers, for any state.

Given the total deposit, denoted by $d>0$, and the repayment plan $q^{n}=q^{n}(\alpha)$ and $\theta=\theta(\alpha)$, described in Lemma 1, the banks' portfolio choice problem in the CM can be written as

$V(d)=\max _{z, k, l \geq 0} \int_{0}^{1}\left[\alpha\left\{u\left(q^{n}\right)+W(0, k, l, 0)\right\}+(1-\alpha)\left\{u\left(q^{*}\right)+W\left(\frac{(1-\theta) z}{(1-\alpha) \pi}, k, l, q^{*}\right)\right\}\right] f(\alpha) d \alpha$,

subject to the balance sheet constraint,

$$
d=z+k+l
$$

In this expression, notice that a non-monitored (monitored) buyer consumes $q^{n}\left(q^{*}\right)$ in the DM, and the bank's long-term assets, $k$ and $l$, are distributed uniformly among all buyers. $W\left(z^{\prime}, k, l, c\right)$ represents the expected value of a buyer entering the next night market with holdings of $z^{\prime}$ real cash balances, $k$ safe assets, $l$ risky assets, and $c$ debt from the DM and is given by

$$
W\left(z^{\prime}, k, l, c\right)=\max _{x, h, d_{+} \geq 0} U(x)-h+\beta V\left(d_{+}\right)
$$


subject to

$$
x+d_{+}+c=h+R(k+\eta \lambda l)+z^{\prime}+T,
$$

and the usual non-negativity constraints, where $T$ denotes the real value of the monetary transfers (or taxes) from the central bank, that is, $T=\phi\left(M_{+}-M\right)=\left(1-\frac{1}{\pi}\right) \phi M_{+}$, and $V\left(d_{+}\right)$is the expected value in the next DM with deposits $d_{+}$. Substituting for $h$,

$$
W\left(z^{\prime}, k, l, c\right)=R(k+\eta \lambda l)+z^{\prime}+T-c+\max _{x \geq 0}\{U(x)-x\}+\max _{d_{+} \geq 0}\left\{-d_{+}+\beta V\left(d_{+}\right)\right\},
$$

implies that the choice of $d_{+}$is independent of the wealth $R(k+\eta \lambda l)+z^{\prime}+T-c$ as in the Lagos and Wright model.

Define

$$
\Upsilon(z) \equiv F\left(\alpha^{*}\right)+\int_{\alpha^{*}}^{1} u^{\prime}\left(q^{n}\right) f(\alpha) d \alpha .
$$

Then, the marginal benefit from real cash balances holding is given by

$$
\frac{1}{\pi} \Upsilon(z)
$$

since when $\alpha \leq \alpha^{*}$, cash is useful only in the CM, where a unit of cash yields a real value $\frac{1}{\pi}$ (as captured in the first term in $\Upsilon$ ), while when $\alpha>\alpha^{*}$, cash is useful in the DM, where a unit of cash yields $\frac{u^{\prime}\left(q^{n}\right)}{\pi}$ (as captured in the second term in $\Upsilon$ ).

Lemma 2 (Banks' Optimal Portfolio Choice) Given deposit $d>0$, the optimal portfolio of banks is described by $k=d-z \geq 0, l=0$, and

$$
z= \begin{cases}z(d) & \text { if } \Upsilon(d) \leq \pi R, \\ d & \text { if } \Upsilon(d)>\pi R,\end{cases}
$$

where $z(d) \in(0, d)$ is a solution to $\Upsilon(z(d))=\pi R$.

Note that since the risky asset is strictly dominated by the safe asset, the bank does not invest in the risky asset at all, that is, $l=0$. Note also that the marginal benefit from cash holdings is positive and is monotonically decreasing in $z$ (see the proof of Lemma 2). Hence, 
if the marginal benefit from holding real balances, $\frac{1}{\pi} \Upsilon$, is greater than the marginal cost, $R$, at $z=d$, then $\Upsilon(z)>\pi R$ for all $z \leq d$ and the bank holds cash only, hence, $z=d$ and $k=0$. Otherwise, the bank's portfolio includes not only cash $z=z(d) \in(0, d)$, but also assets $k>0$.

The last step is to determine the optimal deposits of the buyers, given the deposit contract offered by the banks, $\left(q^{n}, z, k, l\right)$, as described above. The buyer's problem is

$$
\max _{d \geq 0}\{-d+\beta V(d)\}
$$

where $V(d)$ is the buyer's expected value entering the DM with deposit $d>0$ as described above.

For $d<\Upsilon^{-1}(\pi R)$, we have $z=d$ and the Euler equation is $1=\beta V^{\prime}(d)$ or

$$
\frac{\pi}{\beta}=F\left(\frac{d}{\pi q^{*}}\right)+\int_{\frac{d}{\pi q^{*}}}^{1} u^{\prime}\left(\frac{d}{\pi \alpha}\right) f(\alpha) d \alpha \quad(=\Upsilon(d)),
$$

while for $d \geq \Upsilon^{-1}(\pi R)$, we have $z=z(d) \in(0, d)$ and $V^{\prime}(d)=R$, that is, the marginal value of deposits hits the lower bound $R$ for high values of $d$. We therefore have the following result.

Theorem 1 (Monetary Equilibrium without LLR) A monetary equilibrium exists without an LLR, and is unique, where the deposit and cash holdings, denoted by $d_{N}$ and $z_{N}$, satisfy $d_{N}=z_{N} \in\left(0, \pi q^{*}\right)$, and a banking panic occurs with probability $1-F\left(\alpha^{*}\right) \in(0,1)$, where $\alpha^{*}=\frac{d_{N}}{\pi q^{*}}$.

Not surprisingly, without an LLR, banks hold deposits only as cash and no long-term assets, that is, $d_{N}=z_{N} \in\left(0, \pi q^{*}\right)$, because both long-term assets, safe and risky, generate a real return less than the associated costs, $\beta \max \{\eta \lambda R, R\}=\beta R<1$, and there is no use for them in the DM trade. With aggregate money demand uncertainty, the probability of a panic is positive. This creates a situation in which in the absence of an LLR, non-monitored buyers are unable to consume the first best quantity because the bank runs out of cash reserves. The probability of a panic goes to zero following the Friedman rule, that is, $\alpha^{*}=\frac{d_{N}}{\pi q^{*}} \rightarrow 1$ as $\pi \rightarrow \beta$.

The result on the effects of inflation is as follows: 
Corollary 1 (Effects of Inflation) If $\xi>0$ is not too big, the equilibrium deposit level, $d_{N}$, is monotonically decreasing in inflation, and the probability of a banking panic, $1-F\left(\alpha^{*}\right)$, is monotonically increasing in inflation.

A higher inflation yields both a substitution effect and an income effect. The substitution effect occurs because higher inflation raises the cost of holding cash reserves, and, therefore, banks will attempt to economize on such holdings, leading to a lower deposit level. Higher inflation also implies that banks can obtain the same amount of returns by increasing their reserves. In this manner, the income effect leads to an increase in the demand for cash reserves, leading to a higher deposit level. If $\xi$ is not too big, the substitution effect dominates the income effect, which is assumed to be the case throughout this paper, implying that the bank's reserves are decreasing in inflation. As a result, the likelihood that the entire banking system will run out of liquidity increases. This result is consistent with empirical studies (e.g., Demirgüç-Kunt and Detragiache 1998, 2005).

Discussions. Banking panics in our model are a monetary event resulting from a bank's reserve shortage and suspensions of convertibility instead of banking insolvency, like in Champ, Smith, and Williamson (1996) and many others. Our definition captures the situation where a significant number of depositors suddenly demand to redeem bank debt for cash, leading to a shortage of the overall amount of reserves in the banking system and a suspension of convertibility.

So far, we have considered the baseline model with perfect credit and without an LLR, long-term assets are not used in the DM, and banks never invest in them in equilibrium. If perfect credit is not available, the bank's portfolio choice is not trivial. Our earlier paper, Matsuoka and Watanabe (2017), considers secured credit where these assets are used as a collateral in the DM monitored meeting, and shows that banks actually invest in long-term assets even in the absence of an LLR. In this paper, we assume away this channel. Instead, we will consider the role of long-term assets as collateral to obtain loans from the central bank in case of panics. We conjecture, however, that our main insight is not affected by this 
simplification.

Finally, one of the important criticisms of Bagehot's rule is that there is no clear-cut distinction between illiquidity and insolvency during a crisis (e.g., Goodhart, 1987; 1999). We capture this point well because in our model the timings of bank's illiquidity and insolvency are different; illiquidity can occur during a day, while insolvency can occur at the beginning of a night. Thus, the LLR must decide whether to lend its funds to illiquid banks before their asset returns are realized. In such an environment, the banks have an incentive to borrow and default, as we will see below.

\section{The Lender of Last Resort}

In this section, we extend our basic framework and allow the central bank to act as the LLR.

After the realization of $\alpha$, the central bank opens a discount window at the beginning of the DM, and offers private banks an intra-day cash loan with a gross interest rate. The central bank can limitlessly prepare cash for private banks, and so there is no limit to the quantity the central bank can lend. Clearly, private banks do not need additional cash if they have enough cash reserves to cover their depositors' needs, and so the discount window will be activated only when a banking panic occurs. Note that since private banks operate subject to limited liability, the central bank needs a guarantee for their loans' repayment given a possible default by the private banks. That is, the central bank's loans are fully collateralized as in current practice. We assume that the revenue (or loss) earned by the LLR through this lending policy is rebated to (or taxed on) the buyers in a lump sum manner. Finally, we also assume that the members of the central bank committee serve for only one period and are replaced by new members at the end of each period. ${ }^{3}$

With the LLR, a private bank's deposit contract is modified to $\left(q^{n}, z, b, k, l\right)$, where $b$ is the amount of real balances a private bank borrows from the LLR in the event of a banking panic. Note that safe and risky assets are substitutes. In what follows, we therefore consider

\footnotetext{
${ }^{3}$ This allows the economy to sustain a stationary monetary equilibrium with risky assets. Under this assumption, any information about banking defaults in the past would not affect the current LLR policy.
} 
two extreme cases, one with only the safe asset, that is, $k \geq 0=l$, and the other with only the risky asset, that is, $l \geq 0=k$. Banks compare the expected utilities of these two cases and choose the one with the higher utility in equilibrium.

\subsection{Safe Asset}

We first consider the case where private banks invest only in the safe asset. It is now assumed that $^{4}$

$$
R^{C}>\max \{\pi R, 1\}
$$

If $R^{C} \leq \pi R$, banks would avoid the cost of holding cash reserves by not transferring money over time (i.e., by setting $z=0$ ), and so a monetary equilibrium would not exist. In addition, the assumption $R^{C}>1$ guarantees the "pecking order" that the banks first use their cash reserves and next borrow from the LLR. If $R^{C} \leq 1$, the bank would have an incentive to use the discount window loan before using own cash reserves. To derive the monetary equilibrium with the LLR, we follow the same steps as in the previous section.

As mentioned above, since private banks operate subject to limited liability, the central bank needs a guarantee of repayment. We assume that private banks can use their long-term assets as collateral. ${ }^{5}$ Formally, if a private bank holds $k \geq 0$ safe assets and borrows $b \geq 0$ real cash balances, then it should satisfy the borrowing constraint,

$$
R^{C} b \leq R k
$$

The constraint states that a bank that demands and borrows $\frac{b}{\phi_{+}}$yen (in nominal terms) from the central bank after the realization of $\alpha$, must pay back $\frac{R^{C} b}{\phi_{+}}$yen $\left(\frac{R^{C} \phi_{+} b}{\phi_{+}}=R^{C} b\right.$ real balances $)$ during the following night. This quantity must be no greater than the expected return on safe

\footnotetext{
${ }^{4}$ This assumption also captures the view of Bagehot (1873) that "[a very high interest rate] will operate as a heavy fine on unreasonable timidity, and will prevent the greatest number of applications by persons who don't require it. The rate should be raised early in the panic, so that the fine may be paid early; that no one may borrow out of idle precaution without paying well for it; that the banking reserve may be protected as far as possible" (p. 199).

${ }^{5}$ Equivalently, we can assume that the central bank makes a repurchase agreement with a troubled bank, whereby the bank sells some of its long-term assets to the central bank during the day in exchange for money and buys them back for a price of $R^{C}$ during the night.
} 
assets $\frac{R k}{\phi_{+}}$yen. Note that since the central bank loans are intra-day, its marginal cost is free from inflation.

Since the revenue earned by the LLR is rebated to the buyers, the government budget constraint in a given period is now modified as follows:

$$
T=\phi\left(M_{+}-M\right)+\left(R^{C}-1\right) b,
$$

where $b$ is determined by the banks in the previous DM. The first term on the left-hand side (L.H.S.) represents seigniorage, while the second is the profit on the discount window loans.

Given values of $z>0$ and $k \geq 0$, for each realization of $\alpha \in(0,1)$, a private bank's problem of choosing the payment schedule in the DM is described as follows:

$$
\max _{\theta \in[0,1], b \geq 0} \alpha u\left(q^{n}\right)+(1-\theta) \frac{z}{\pi}-R^{C} b
$$

subject to the borrowing constraint (4) and

$$
\alpha q^{n}=\frac{\theta z}{\pi}+b
$$

The first order conditions are (1) and

$$
u^{\prime}\left(q^{n}\right)-R^{C}+\mu_{b}-\mu_{k} R^{C}=0
$$

where $\mu_{b} \geq 0$ is the Lagrange multiplier of the non-negativity constraint $b \geq 0$ and $\mu_{k} \geq 0$ is the Lagrange multiplier of the borrowing constraint (4). The occurrence of a banking panic is described by the same critical value as before, $\alpha^{*} \equiv \frac{z}{\pi q^{*}}$, determined by the same condition (1). The condition (5) determines two more critical values (see below) that describe the borrowing quantity of private banks in the case of panics.

Lemma 3 (Banks' Optimal Payment Plan with the LLR and the Safe Asset) Given $z>0, k \geq 0=l$, the optimal payment plan of banks with the safe asset in the presence of the 
LLR is described by $q^{m}=q^{*}$ and $\theta=\theta(\alpha)$, similar to that in Lemma 1, and

$$
b(\alpha)=\left\{\begin{array}{ll}
0 & \text { if } 0<\alpha \leq \alpha^{* *}, \\
\alpha u^{-1 \prime}\left(R^{C}\right)-\frac{z}{\pi} & \text { if } \alpha^{* *}<\alpha<\alpha^{* * *}, \\
\frac{R k}{R^{C}} & \text { if } \alpha^{* * *} \leq \alpha<1,
\end{array} \quad \text { and } \quad q^{n}(\alpha)= \begin{cases}q^{*} & \text { if } 0<\alpha<\alpha^{*}, \\
\frac{z}{\alpha \pi} & \text { if } \alpha^{*} \leq \alpha \leq \alpha^{* *}, \\
u^{-1 \prime}\left(R^{C}\right) & \text { if } \alpha^{* *}<\alpha<\alpha^{* * *}, \\
\frac{R^{C}}{\pi} z+R k & \text { if } \alpha^{* * *} \leq \alpha<1,\end{cases}\right.
$$

where

$$
\alpha^{*} \equiv \frac{z}{\pi q^{*}}, \quad \alpha^{* *} \equiv \min \left\{\frac{z}{\pi u^{-1 \prime}\left(R^{C}\right)}, 1\right\}, \quad \text { and } \quad \alpha^{* * *} \equiv \min \left\{\frac{\frac{R^{C}}{\pi} z+R k}{R^{C} u^{-1 \prime}\left(R^{C}\right)}, 1\right\} .
$$

As in the model without the LLR, banking panics will never occur when $\alpha \in\left(0, \alpha^{*}\right)$ and private banks do not need to borrow from the central bank. A banking panic occurs when $\alpha \in\left[\alpha^{*}, 1\right)$ in any one of the following three cases: for $\alpha \in\left[\alpha^{*}, \alpha^{* *}\right]$, banks exhaust cash reserves but do not borrow because the benefit of the LLR is relatively low; for $\alpha \in\left(\alpha^{* *}, \alpha^{* * *}\right)$, banks borrow cash as much as they want; for $\alpha \in\left[\alpha^{* * *}, 1\right)$, the borrowing constraint is binding and banks borrow the maximum level, $R k$. Note that the assumption $R^{C}>1$ guarantees the condition $\alpha^{*}<\alpha^{* *}$ for any $z>0$.

Given the repayment plan, we now consider the portfolio choice. A bank's problem is described by the same value function as in (2), but now the value function in the CM is given by

$$
W\left(z^{\prime}, k, 0, c, b\right)=R k+z^{\prime}+T-c-R^{C} b+\max _{x \geq 0}\{U(x)-x\}+\max _{d_{+} \geq 0}\left\{-d_{+}+\beta V^{s}\left(d_{+}\right)\right\},
$$

where the payment amount of $R^{C} b$ will be made to the LLR. Applying this, $\theta=\min \left\{1, \frac{\alpha}{\alpha^{*}}\right\}$, the result in Lemma 3 and the balance sheet constraint, $d=z+k$, to the value function (2), we have:

$$
\begin{aligned}
& V^{s}(d)=\max _{0 \leq z \leq d} \int_{0}^{\alpha^{*}}\left[\alpha u\left(q^{*}\right)+\left(1-\frac{\alpha}{\alpha^{*}}\right) \frac{z}{\pi}\right] f(\alpha) d \alpha+\int_{\alpha^{*}}^{\alpha^{* *}} \alpha u\left(\frac{z}{\alpha \pi}\right) f(\alpha) d \alpha \\
+ & \int_{\alpha^{* *}}^{\alpha^{* * *}}\left[\alpha u\left(u^{-1 \prime}\left(R^{C}\right)\right)-R^{C}\left(\alpha u^{-1 \prime}\left(R^{C}\right)-\frac{z}{\pi}\right)\right] f(\alpha) d \alpha+\int_{\alpha^{* * *}}^{1}\left[\alpha u\left(\frac{\frac{R^{C}}{\pi} z+R(d-z)}{R^{C} \alpha}\right)-R(d-z)\right] f(\alpha) d \alpha \\
+ & \{1-E(\alpha)\}\left\{u\left(q^{*}\right)-q^{*}\right\}+R(d-z)+T+\max _{x \geq 0}\{U(x)-x\}+\max _{d_{+} \geq 0}\left\{-d_{+}+\beta V^{s}\left(d_{+}\right)\right\},
\end{aligned}
$$


where $E(\alpha) \equiv \int_{0}^{1} \alpha f(\alpha) d \alpha$.

Let us define

$$
\begin{aligned}
& \Psi_{z}(z, d) \equiv F\left(\alpha^{*}\right)+\int_{\alpha^{*}}^{\alpha^{* *}} u^{\prime}\left(\frac{z}{\alpha \pi}\right) f(\alpha) d \alpha+\left[F\left(\alpha^{* * *}\right)-F\left(\alpha^{* *}\right)\right] R^{C}+\int_{\alpha^{* * *}}^{1} u^{\prime}\left(\frac{\frac{R^{C}}{\pi} z+R(d-z)}{R^{C} \alpha}\right) f(\alpha) d \alpha, \\
& \Psi_{k}(z, d) \equiv F\left(\alpha^{* * *}\right)+\frac{1}{R^{C}} \int_{\alpha^{* * *}}^{1} u^{\prime}\left(\frac{\frac{R^{C}}{\pi} z+R(d-z)}{R^{C} \alpha}\right) f(\alpha) d \alpha .
\end{aligned}
$$

Then, noting $\alpha^{* * *} \leq 1$, the first order condition of the optimal portfolio choice is:

$$
\Psi(z, d) \equiv \frac{1}{\pi} \Psi_{z}(z, d)-R \Psi_{k}(z, d) \geq 0 \quad(=\text { if } z<d)
$$

Denote by $z=z(d)$ a solution to $(6)$ and $k(d) \equiv d-z(d)$. Then, given the optimal portfolio $(z(d), k(d))$, the deposit choice of depositors is described by the Euler equation, $-1+\beta V^{s^{\prime}}(d)=$ 0 , where

$$
V^{s \prime}(d)=\frac{\partial z}{\partial d} \frac{\partial V^{s}(d)}{\partial z}+\frac{\partial V^{s}(d)}{\partial d}
$$

There are two cases. For $z=z(d) \in(0, d)$ (an interior solution), by applying the envelope condition, we have $\Psi(z, d)=\frac{\partial V^{s}(d)}{\partial z}=0$ and $V^{s \prime}(d)=\frac{\partial V^{s}(d)}{\partial d}=R \Psi_{k}(z, d)$, and so the Euler equation is

$$
\Psi_{k}(z, d)=\frac{1}{\beta R} .
$$

Hence, an equilibrium, denoted by $\left(z_{S}, d_{S}\right)>0$, is identified by $(7)$ and

$$
\Psi_{z}(z, d)=\frac{\pi}{\beta}
$$

For $z=d$ (the corner solution), we have $\alpha^{* *}=\alpha^{* * *}, \Psi(z, d)=\frac{\partial V^{s}(d)}{\partial z}>0$ and $V^{s \prime}(d)=$ $\Psi(z, d)+R \Psi_{k}(z, d)=\frac{\Psi_{z}(z, d)}{\pi}$, and so the Euler equation is given by (3); since the bank does not hold any long-term assets, it cannot borrow from the LLR, $b=0$.

Proposition 1 (Monetary Equilibrium with the LLR and the Safe Asset) With the $L L R$ and the safe asset, a monetary equilibrium with bank deposits exists and is unique such that cash reserves and bank deposits satisfy

$$
z= \begin{cases}z_{S}\left(<d_{S}\right) & \text { for } R^{C} \in\left(\pi R, R^{C *}\right], \\ z_{N}\left(=d_{N}\right) & \text { for } \quad R^{C} \in\left(R^{C *}, \infty\right),\end{cases}
$$




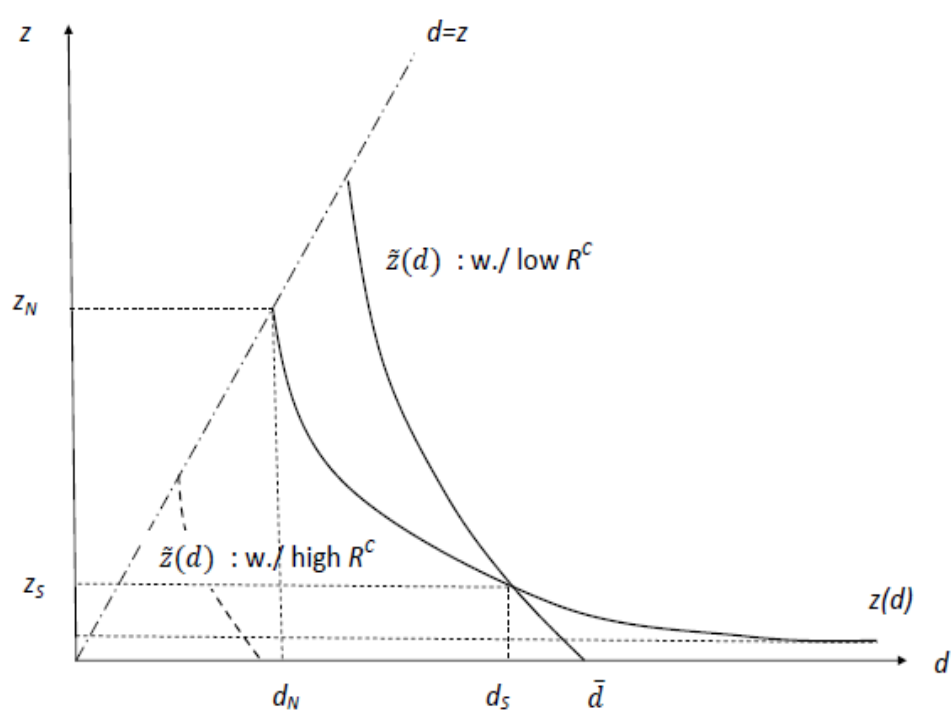

Fig 3: Monetary equilibrium with LLR and safe asset

with some critical value $R^{C *} \in(\pi R, \infty)$, and $z_{S} \leq z_{N}$ and $d_{S} \geq d_{N}$. Further, whenever $R^{C}<R^{C *}$, it holds that $\alpha^{* * *}<1$.

As illustrated in Figure 3, a monetary equilibrium with a positive amount of the safe asset can be identified using two curves: $\tilde{z}=\tilde{z}(d)$, which is constructed using the Euler equation (7), and $z=z(d)$, which is constructed using the first order condition (8). Both these curves are downward sloping, because intuitively, cash and long-term assets are substitutes when the LLR lending is available during panics. As long as the loan rate from the LLR is not too high, that is, $R^{C} \in\left(\pi R, R^{C *}\right]$, the $\tilde{z}(d)$ curve intersects the $z(d)$ curve at $z=z_{S}<z_{N}$ and $d=d_{S}>d_{N}$ where the bank invests in a long-term safe asset $d_{S}-z_{S}>0$, and the discount window lending is activated in case of panics. In contrast, if the rate is sufficiently high, that is, $R^{C}>R^{C *}$, banks will never borrow from the discount window, and the equilibrium allocation is identical to the one without the LLR as described in Theorem 1.

In the presence of the LLR, a long-term asset has a benefit in the DM that allows the bank to use the discount window lending during a banking panic. To derive the liquidity premium 
on the safe asset, rewriting (7) yields

$$
\frac{1-\beta R}{\beta R}=\int_{\alpha^{* * *}}^{1}\left\{\frac{u^{\prime}\left(q^{n}\right)}{R^{C}}-1\right\} f(\alpha) d \alpha .
$$

The left-hand side of this equation represents the cost of investing an additional unit of the safe asset, and the right-hand side represents the liquidity premium. When the borrowing constraint (4) is not binding, which occurs with probability $F\left(\alpha^{* * *}\right)$, an additional unit of the safe asset has no effects in the DM, and thus the liquidity return is zero. When the borrowing constraint (4) is binding, which occurs with probability $1-F\left(\alpha^{* * *}\right)$, a bank can use $\frac{1}{R}$ unit of the safe asset to borrow $\frac{1}{R^{C}}$ units of real cash balances, which allows each non-monitored buyer to acquire $\frac{1}{\alpha R^{C}}$ units of special goods with a total marginal utility of $\frac{\alpha u^{\prime}\left(q^{n}\right)}{\alpha R^{C}}$.

The banks always have the option not to borrow from the discount window, and, thus, the LLR must be welfare improving if it is used. It mitigates the loss of banking panics by providing liquidity, leading to a higher level of deposit and consumption in the DM nonmonitored meeting. The LLR will, however, reduce the incentive of banks to invest in liquid assets. As a result, banks hold a lower amount of cash reserves, and thus the LLR will increase the probability of banking panics. In Figure 4, the critical value without the LLR is represented by $\alpha_{N}^{*}$, and those with the LLR are represented by $\alpha_{S}^{*}, \alpha_{S}^{* *}$, and $\alpha_{S}^{* * *}$.

Corollary 2 (Implication of LLR) The LLR is welfare improving, but increases the probability of a banking panic.

We now study the consequences of changing $\pi$ and $R^{C}$. With corner solutions, since all deposits are invested in cash reserves and banks do not borrow from the central bank, that is, $\left(z_{S}, d_{S}\right)=\left(z_{N}, d_{N}\right)$, the comparative static results are identical to those described in Proposition 1. Using interior solutions, we obtain:

Corollary 3 (Effects of Inflation and Loan Rate) Suppose that $\xi>0$ is not too big. Then, the interior solutions with the safe asset $\left(z_{S}, d_{S}\right)$ satisfy

$$
\frac{\partial z_{S}}{\partial \pi}<0, \quad \frac{\partial d_{S}}{\partial \pi}>0, \quad \frac{\partial z_{S}}{\partial R^{C}}>0, \text { and } \frac{\partial d_{S}}{\partial R^{C}}<0 .
$$




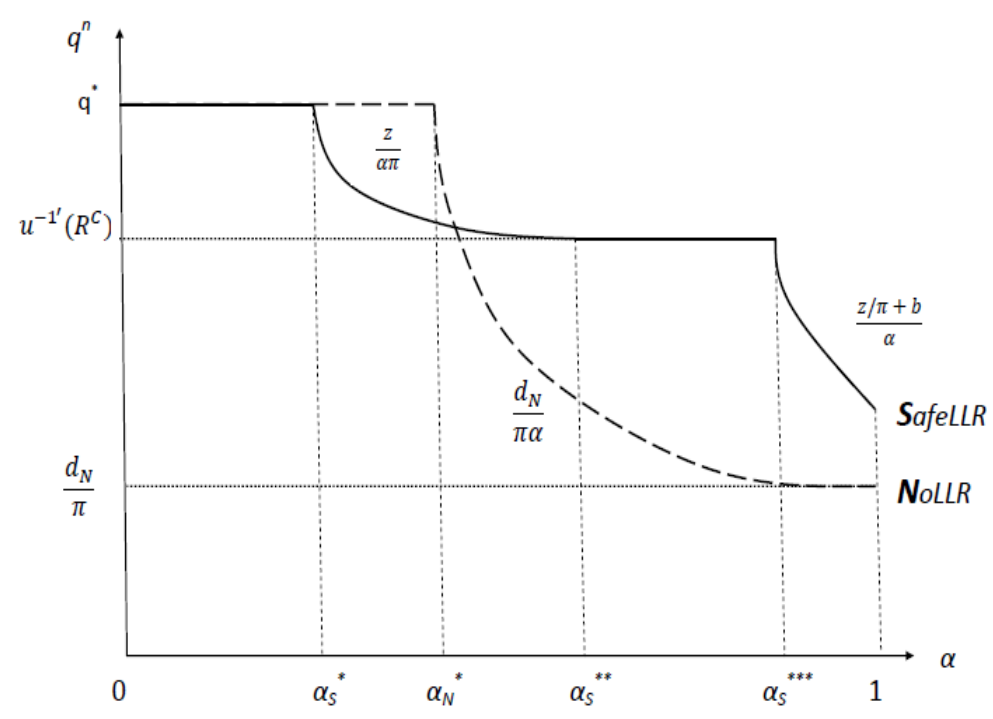

Fig 4: Monetary equilibrium with versus without LLR

\section{Furthermore,}

$$
\frac{\partial \alpha^{*}}{\partial \pi}<0, \quad \frac{\partial \alpha^{* *}}{\partial \pi}<0, \quad \frac{\partial \alpha^{* * *}}{\partial \pi}=0, \quad \frac{\partial \alpha^{*}}{\partial R^{C}}>0, \quad \frac{\partial \alpha^{* *}}{\partial R^{C}}>0, \quad \text { and } \quad \frac{\partial \alpha^{* * *}}{\partial R^{C}}=0 .
$$

If $\xi>0$ is not too big (i.e., the substitution effect dominates the income effect), a higher inflation leads to a higher money holding cost, and a higher incentive for banks to economize their cash reserves, leading to a positive effect of inflation on the probability of a banking panic and the likelihood that banks borrow from the central bank. Somewhat surprisingly, the effect of an increase in $\pi$ on $d$ differs depending on the presence of the LLR. In the case with the LLR, at a higher inflation, banks attempt to rely more on the central bank loans to avoid higher money holding costs. To do this, they have to collect more deposits and invest more in long-term assets as collateral for loans. In contrast, there is no such channel without the LLR, and, thus, the deposit level is simply decreasing in inflation, as most monetary general equilibrium models predict. Inflation has no effect on $\alpha^{* * *}$ because the negative impact on reserves and the positive impact on the safe asset cancel out. An increase in $R^{C}$ gives the bank an incentive to be self-guarding and increase their cash reserves, leading to positive impacts on $\alpha^{*}$ and $\alpha^{* *}$, but since it makes the deposit contracts less attractive the deposit level will 
be lower.

\subsection{Risky Asset}

Consider next the case of the risky asset. An important difference is that given limited liability, banks must default when the risky asset produces nothing. Since banks are able to honor their promise to repay the central bank loans only if the project is successful, the expected payment rate of the discount window loan with the risky asset is reduced to $\eta R^{C}$. In line with the previous analysis, we assume that

$$
R^{C}>\max \left\{\underline{R}^{C}, \frac{1}{\eta}\right\}
$$

where $\underline{R}^{C} \equiv \pi R /\{1-\beta \eta(\lambda-1) R\}>\pi R$. If $R^{C} \leq \underline{R}^{C}$, the demand for cash reserves would then be zero, and money would not circulate between periods. As before, the condition $R^{C}>1 / \eta$ guarantees the "pecking order" of the banks' use of cash reserves.

Note that given the information structure associated with the observability of the risky asset returns, banks face the same borrowing constraint as described in (4) for the discount window borrowing.

With a risky asset, there is an issue of who should take on the financial burden of losses associated with banking defaults on the discount window loan. Ultimately, additional taxes levied on agents should compensate for these losses. This implies, together with the constant money supply rule, that the expected lump sum tax is given by

$$
E(T)=\phi\left(M_{+}-M\right)+\left(\eta R^{C}-1\right) b
$$

With a risky asset, the optimal payment plan of private banks is modified as follows.

Lemma 4 (Banks' Optimal Payment Plan with the LLR and the Risky Asset) Given $z>0, l \geq 0=k$, the optimal payment plan of banks with the risky asset in the presence of 
the LLR is described by $q^{m}=q^{*}$ and $\theta=\theta(\alpha)$, the same as in Lemma 1, and

$$
b(\alpha)=\left\{\begin{array}{ll}
0 & \text { if } 0<\alpha \leq \alpha_{\eta}^{* *}, \\
\alpha u^{-1 \prime}\left(\eta R^{C}\right)-\frac{z}{\pi} & \text { if } \alpha_{\eta}^{* *}<\alpha<\alpha_{\eta}^{* * *}, \\
\frac{R l}{R^{C}} & \text { if } \alpha_{\eta}^{* * *} \leq \alpha<1,
\end{array} \quad \text { and } \quad q^{n}(\alpha)= \begin{cases}q^{*} & \text { if } 0<\alpha \leq \alpha^{*}, \\
\frac{z}{\alpha \pi} & \text { if } \alpha^{*} \leq \alpha \leq \alpha_{\eta}^{* *}, \\
u^{-1 \prime}\left(\eta R^{C}\right) & \text { if } \alpha_{\eta}^{* *}<\alpha<\alpha_{\eta}^{* * *}, \\
\frac{R^{C}}{R^{C} \alpha}(R l & \text { if } \alpha_{\eta}^{* * *} \leq \alpha<1,\end{cases}\right.
$$

where

$$
\alpha^{*} \equiv \frac{z}{\pi q^{*}}, \quad \alpha_{\eta}^{* *} \equiv \min \left\{\frac{z}{\pi u^{-1 \prime}\left(\eta R^{C}\right)}, 1\right\}, \quad \text { and } \quad \alpha_{\eta}^{* * *} \equiv \min \left\{\frac{\frac{R^{C}}{\pi} z+R l}{R^{C} u^{-1 \prime}\left(\eta R^{C}\right)}, 1\right\} .
$$

The solutions are quite similar to the ones of Lemma 3, except that, since the borrowing cost associated with the discount window is reduced, that is, $u^{-1 \prime}\left(\eta R^{C}\right)>u^{-1 \prime}\left(R^{C}\right)$, the bank increases the amount of borrowing compared to the case with a safe asset.

Given the repayment plan with a risky asset, the value function in the DM is modified to

$$
\begin{aligned}
V^{r}(d) & =\max _{0 \leq z \leq d} \int_{0}^{\alpha^{*}}\left[\alpha u\left(q^{*}\right)+\left(1-\frac{\alpha}{\alpha^{*}}\right) \frac{z}{\pi}\right] f(\alpha) d \alpha+\int_{\alpha^{*}}^{\alpha_{\eta}^{* *}} \alpha u\left(\frac{z}{\alpha \pi}\right) f(\alpha) d \alpha \\
& +\int_{\alpha_{\eta}^{* *}}^{\alpha_{\eta}^{* * *}}\left[\alpha u\left(u^{-1 \prime}\left(\eta R^{C}\right)\right)-\eta R^{C}\left(\alpha u^{-1 \prime}\left(\eta R^{C}\right)-\frac{z}{\pi}\right)\right] f(\alpha) d \alpha \\
& +\int_{\alpha_{\eta}^{* * *}}^{1}\left[\alpha u\left(\frac{\frac{R^{C}}{\pi} z+R(d-z)}{R^{C} \alpha}\right)-\eta R(d-z)\right] f(\alpha) d \alpha \\
& +\{1-E(\alpha)\}\left\{u\left(q^{*}\right)-q^{*}\right\}+\eta \lambda R(d-z)+T+\max _{x \geq 0}\{U(x)-x\}+\max _{d_{+} \geq 0}\left\{-d_{+}+\beta V^{r}\left(d_{+}\right)\right\} .
\end{aligned}
$$

Based on this value function, a monetary equilibrium, denoted by $\left(z_{R}, d_{R}\right)$, with $l_{R}=d_{R}-z_{R}>$ 0 is characterized by the following two implicit equations:

$$
\begin{aligned}
& \Phi_{z}(z, d) \equiv F\left(\alpha^{*}\right)+\int_{\alpha^{*}}^{\alpha_{\eta}^{* *}} u^{\prime}\left(\frac{z}{\alpha \pi}\right) f(\alpha) d \alpha+\left[F\left(\alpha_{\eta}^{* * *}\right)-F\left(\alpha_{\eta}^{* *}\right)\right] \eta R^{C}+\int_{\alpha_{\eta}^{* * *}}^{1} u^{\prime}\left(\frac{\frac{R^{C}}{\pi} z+R(d-z)}{R^{C} \alpha}\right) f(\alpha) d \alpha=\frac{\pi}{\beta}, \\
& \Phi_{l}(z, d) \equiv \eta F\left(\alpha_{\eta}^{* * *}\right)+\frac{1}{R^{C}} \int_{\alpha_{\eta}^{* * *}}^{1} u^{\prime}\left(\frac{\frac{R^{C}}{\pi} z+R(d-z)}{R^{C} \alpha}\right) f(\alpha) d \alpha+\eta(\lambda-1)=\frac{1}{\beta R}
\end{aligned}
$$


According to the Euler equation (11), the liquidity premium on the risky asset should satisfy:

$$
\frac{1-\beta \eta \lambda R}{\beta \eta \lambda R}=\frac{1}{\lambda} \int_{\alpha_{\eta}^{* * *}}^{1}\left\{\frac{u^{\prime}\left(q^{n}\right)}{\eta R^{C}}-1\right\} f(\alpha) d \alpha .
$$

The cost of investing an additional unit of the risky asset should equal the liquidity premium. When the borrowing constraint is not binding, which occurs with probability $F\left(\alpha_{\eta}^{* * *}\right)$, the liquidity return is zero since an additional unit of the risky asset has no effect in the DM. When the borrowing constraint is binding, which occurs with probability $1-F\left(\alpha_{\eta}^{* * *}\right)$, the liquidity return is positive since a bank can use $\frac{1}{\eta \lambda R}$ units of the risky asset to borrow $\frac{1}{\eta R^{C}}$ units of real cash balances, which allows each non-monitored buyer to acquire $\frac{1}{\alpha \eta R^{C}}$ units of special goods and its total marginal utility is $\frac{\alpha u^{\prime}\left(q^{n}\right)}{\alpha \eta R^{C}}$. Finally, since only a fraction $\frac{R}{\lambda R}$ of the successful return of the risky asset can be pledgeable, the liquidity return is simply discounted by $\frac{1}{\lambda}$.

Identifying a monetary equilibrium will follow the same steps as before.

Proposition 2 (Monetary Equilibrium with the LLR and the Risky Asset) With the LLR and risky asset, a monetary equilibrium with bank deposits exists and is unique so that the cash reserve balances and the bank's deposits satisfy

$$
z= \begin{cases}z_{R}\left(<d_{R}\right) & \text { for } \quad R^{C} \in\left(\underline{R}^{C}, \hat{R}^{C *}\right], \\ z_{N}\left(=d_{N}\right) & \text { for } \quad R^{C} \in\left(\hat{R}^{C *}, \infty\right),\end{cases}
$$

with some critical value $\hat{R}^{C *} \in\left(\underline{R}^{C}, \infty\right)$, and $z_{S}<z_{R}$ and $d_{R}>d_{N}$ for any $\eta \in(0,1)$. Further, whenever $R^{C}<\hat{R}^{C *}$, it holds that $\alpha_{\eta}^{* * *}<1$.

As in the case with a safe asset, a monetary equilibrium with a positive amount of the risky asset can be identified by using two curves: $\tilde{z}=\tilde{z}_{\eta}(d)$, which is constructed using (11), and $z=z_{\eta}(d)$, which is constructed using (10), as illustrated in Figure 5. The $z_{\eta}(d)$ curve with a risky asset pivots down, centered at the monetary equilibrium allocation with no LLR, $\left(z_{N}, d_{N}\right)$, relative to that with a safe asset. This occurs because the expected payment cost 


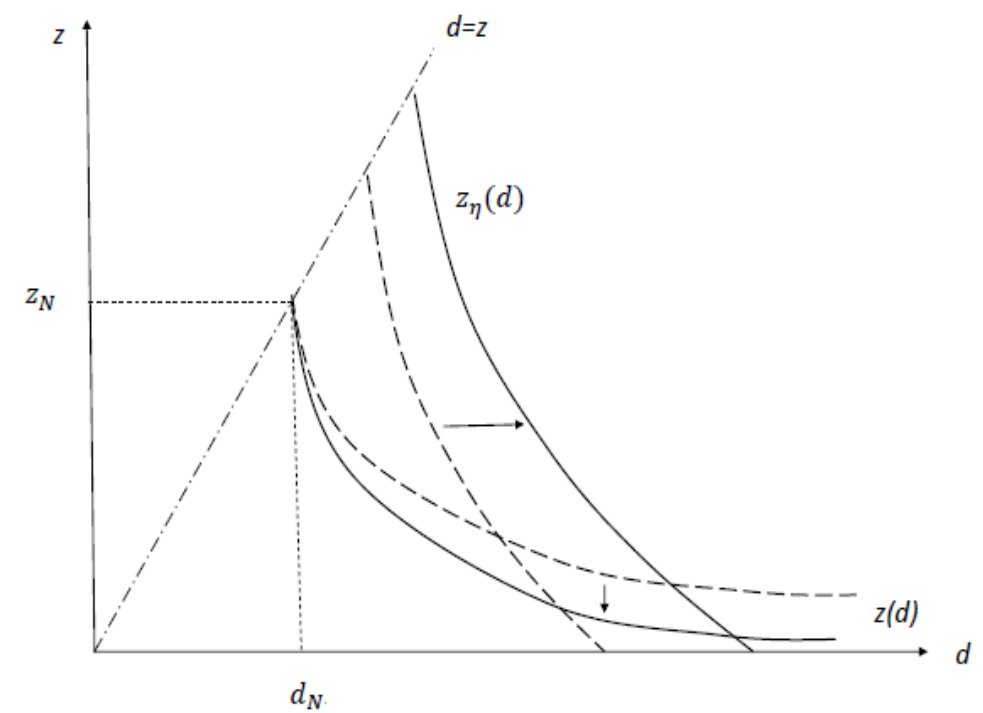

Fig 5: Monetary equilibrium with LLR and risky asset

of the discount window lending is lower with the risky asset than the safe asset, and so given values of $d>0$, the bank has a higher incentive to invest in long-term asset, leading to a higher crowding out of cash reserves. Whether the $\tilde{z}=\tilde{z}_{\eta}(d)$ curve with the risky asset is located below or above the one with the safe asset is determined by the relative size of the cost advantage versus the lower expected return of the risky asset. The figure illustrates a situation where the former benefit outweighs the latter cost.

As before, the LLR is beneficial since it mitigates the loss of banking panics, $d_{R}>d_{N}$ and $z_{R}<z_{N}$, but accompanies a higher probability of banking panics in the first place.

The following comparative static results and their intuitions are quite similar to the ones with a safe asset. The proof is lengthy but is quite similar to the one offered in Corollary 3 . We therefore do not provide it here (available upon request).

Corollary 4 (Effects of Inflation and Loan Rate) Suppose that $\xi>0$ is not too big. Then, the interior solutions with the risky asset satisfy

$$
\frac{\partial z_{R}}{\partial \pi}<0, \quad \frac{\partial d_{R}}{\partial \pi}>0, \quad \frac{\partial z_{R}}{\partial R^{C}}>0, \quad \text { and } \frac{\partial d_{R}}{\partial R^{C}}<0 .
$$


Furthermore,

$$
\frac{\partial \alpha^{*}}{\partial \pi}<0, \quad \frac{\partial \alpha_{\eta}^{* *}}{\partial \pi}<0, \quad \frac{\partial \alpha_{\eta}^{* * *}}{\partial \pi}=0, \quad \frac{\partial \alpha^{*}}{\partial R^{C}}>0, \quad \frac{\partial \alpha_{\eta}^{* *}}{\partial R^{C}}>0, \quad \text { and } \frac{\partial \alpha_{\eta}^{* * *}}{\partial R^{C}}=0 .
$$

\subsection{Asset Choice}

We now study the optimal asset choice of private banks in the presence of the LLR. As mentioned before, safe and risky assets are substitutes, and so depositors choose the higher expected utilities of these two assets. Hence, the problem is

$$
\max \left\{-d_{S}+\beta V^{s}\left(d_{S}\right),-d_{R}+\beta V^{r}\left(d_{R}\right)\right\}
$$

Let us define the difference between the net expected values of the safe and risky assets as:

$$
\Delta\left(R^{C}, \eta\right) \equiv(1-\beta)\left[\left\{-d_{S}+\beta V^{s}\left(d_{S}\right)\right\}-\left\{-d_{R}+\beta V^{r}\left(d_{R}\right)\right\}\right] .
$$

Clearly, the safe asset is selected if $\Delta\left(R^{C}, \eta\right)>0$, while the risky asset is selected if $\Delta\left(R^{C}, \eta\right)<$ 0.

The next lemma establishes some properties of $\Delta\left(R^{C}, \eta\right)$.

Lemma 5 1. If $R^{C}>\max \left\{R^{C *}, \hat{R}^{C *}\right\}$, then $\Delta\left(R^{C}, \eta\right)=0$.

2. If $R^{C} \in\left[R^{C *}, \hat{R}^{C *}\right)$, then $\Delta\left(R^{C}, \eta\right)<0$.

3. If $R^{C} \in\left[\hat{R}^{C *}, R^{C *}\right)$, then $\Delta\left(R^{C}, \eta\right)>0$.

4. $\lim _{\eta \rightarrow 1} \Delta\left(R^{C}, \eta\right)=0$.

5. $\lim _{\eta \rightarrow 1} \frac{\partial \Delta}{\partial R^{C}}\left(R^{C}, \eta\right)=0$.

6. If $\eta \lambda$ and $\beta R$ are very close to 1 , then $\lim _{R^{C} \rightarrow \underline{R}^{C}} \Delta\left(R^{C}, \eta\right)<0$.

The first property follows immediately from the above discussion and Propositions 1 and 2 . If $R^{C}>\max \left\{R^{C *}, \hat{R}^{C *}\right\}$, it follows that $-d_{S}+\beta V^{s}\left(d_{S}\right)=-d_{R}+\beta V^{r}\left(d_{R}\right)=-d_{N}+\beta V\left(d_{N}\right)$, so that the discount window lending is not used, and asset choice becomes irrelevant. To examine the second property, suppose $R^{C} \in\left[R^{C *}, \hat{R}^{C *}\right)$. Then, since the loan rate $R^{C}$ is greater than the threshold rate at which the safe asset is used as collateral $\left(R^{C *}\right)$, but less than the threshold 
rate at which the risky asset is used $\left(\hat{R}^{C *}\right)$, the bank is willing to invest in the risky asset. That is, moral hazard occurs. Banks can borrow from the discount window and default with probability $1-\eta$. To analyze the third property, suppose $R^{C} \in\left[\hat{R}^{C *}, R^{C *}\right)$. Then, applying an argument to the second, $R^{C}$ is greater than the threshold rate of the risky asset but less than the rate of the safe asset, and so banks use the safe asset to borrow money from the discount window. Banks behave prudently and never default on the loans. The intuition for the fourth property is that if $\eta$ is very close to unity, the safe and risky assets are fundamentally the same and the net expected values are equalized. Note here that $\eta \rightarrow 1$ implies that the only admissible parameter value is $\lambda \rightarrow 1$ given $\lambda>1$ and $\eta \lambda \leq 1$. The fifth property states that the effect of the lending rate on the choice of investment becomes negligible as $\eta$ gets closer to unity. This property is in sharp contrast to the conventional view that a higher lending rate has an impact on moral hazard. The final property states that if $R^{C}$ is close to $\underline{R}^{C}$, banks with risky assets will hold almost no cash reserves and rely on the discount window because it is free from inflation costs. On the other hand, banks with the safe asset will hold a positive amount of cash reserves since $\underline{R}^{C}>\pi R$ and will use the discount window loan only when they exhaust the reserves. Since the safe asset's advantage in returns will disappear if $\eta \lambda$ is sufficiently close to unity, and banks can avoid inflation costs by investing in the risky asset, the risky asset will dominate the safe asset as $R^{C} \rightarrow \underline{R}^{C}$. This advantage of the risky asset becomes greater as the cost of holding collateral becomes small, that is, $R \rightarrow \frac{1}{\beta}$. The last two properties of Lemma 5 are the key building blocks for Proposition 3.

The next lemma provides a characterization of $R^{C *} \gtrless \hat{R}^{C *}$.

Lemma 6 There exists $(\eta \lambda)^{*} \in\left(\frac{1}{\pi R}, 1\right)$ such that $R^{C *}<\hat{R}^{C *}$ if $\eta \lambda \in\left((\eta \lambda)^{*}, 1\right]$ and $R^{C *}>$ $\hat{R}^{C *}$ if $\eta \lambda \in\left(0,(\eta \lambda)^{*}\right)$.

Combining Lemmas 5 and 6, we can say that if the expected return on the risky asset, $\eta \lambda$, is sufficiently high, the risky asset is also selected for $R^{C} \in\left[\underline{R}^{C}, \hat{R}^{C *}\right)$. In this case, since the risky asset is always selected whenever the discount window is activated, controlling the lending rate is not effective in preventing the banks from taking excessive risks. 
To summarize, we provide the following proposition.

Proposition 3 (Moral Hazard) In a monetary equilibrium with the LLR, the discount window is activated if and only if the lending rate is low, $R^{C}<\max \left\{R^{C *}, \hat{R}^{C *}\right\}$. When $L L R$ lending is used, private banks will invest in the risky asset rather than the safe asset if the expected return of the risky asset is sufficiently high and the cost of holding the collateral is sufficiently small.

Relative to the safe asset, the risky asset has a cost advantage, but a relatively lower expected return. Thus, if the expected return of the risky asset is not too low, the risky asset will be selected, and banking defaults can occur in equilibrium. Notice here that banking panics and banking defaults are correlated. The risky asset leads to a higher deposit level than the safe asset does, but to lower cash reserves, $z_{R}<z_{S}$, leading to a higher probability of banking panics. Thus, despite the higher probability of banking panics, the risky asset can better mitigate the loss of panics since the banks can borrow more during a panic, that is, $u^{-1 \prime}\left(\eta R^{C}\right)>u^{-1 \prime}\left(R^{C}\right)$.

Historically, discount window loans made during banking crises are often defaulted partially (sometimes totally) or their payback dates are extended since it is difficult for the LLR to distinguish between an illiquid and an insolvent bank. For example, the Bank of Japan provided emergency special loans (called toku-yu) to 114 selected banks in response to the panic of 1927, but about half of the rescued banks had been insolvent and were overdue in their repayments in 1933. Furthermore, the Bank of Japan could not collect more than 52 million yen in loans even in 1952 (see Yokoyama, 2018). Since, in the model, the timings of illiquidity and insolvency are different and there is asymmetric information about the quality of a bank's portfolio, our model captures some of the important elements of the LLR policy.

To further explore the equilibrium outcomes, we use some numerical examples. We assume $u(q)=q^{1-\xi} / 1-\xi$ with $\xi>0$, and $\alpha$ is uniformly distributed, with the following parameter values: $\beta=0.96, R=1.03, \lambda=1.1, \xi=1.3$, and $\pi=1.03$. The top panel of Table 1 summarizes the result with $\eta=0.9(\eta \lambda=0.99)$, where the risky asset is selected for any 
$R^{C}<\hat{R}^{C *}=1.3308$, that is, $\Delta\left(R^{C}, \eta\right)<0$. The lower panel of Table 1 illustrates the result with $\eta=0.8925(\eta \lambda=0.9818)$ where the safe asset is selected for any $R^{C}<R^{C *}=1.2911$ and $\Delta\left(R^{C}, \eta\right)>0$. Clearly, for values of $\eta \lambda<0.9818$, equilibrium allocations with the safe asset are not affected by $\eta$ and $\lambda$. In any case, an increase in $R^{C}$ raises the bank's cash reserves and reduces deposits, leading to higher cutoffs, $\alpha_{R}^{*}$ and $\alpha_{R}^{* *}$, or $\alpha_{S}^{*}$ and $\alpha_{S}^{* *}$, but $\alpha_{R}^{* * *}$ or $\alpha_{S}^{* * *}$ remains unchange. Once $R^{C}$ exceeds the threshold $\hat{R}^{C *}$ or $R^{C *}$, banks will no longer use the central bank loans.

\begin{tabular}{|c|c|c|c|c|c|}
\hline$R^{C}$ & $\eta \lambda$ & $\left(z_{R}, d_{R}\right)$ & $\left(\alpha_{R}^{*}, \alpha_{R}^{* *}, \alpha_{R}^{* * *}\right)$ & $\Delta\left(R^{C}, \eta\right)$ & Types of Equilibrium \\
\hline \hline 1.20 & 0.99 & $(0.4082,0.8557)$ & $(0.3963,0.4205,0.8280)$ & -0.0039 & Risky \\
1.23 & 0.99 & $(0.5578,0.8255)$ & $(0.5416,0.5856,0.8280)$ & -0.0022 & Risky \\
1.26 & 0.99 & $(0.6432,0.7988)$ & $(0.6245,0.6879,0.8280)$ & -0.0014 & Risky \\
\hline \hline 1.20 & 0.9818 & $(0.6734,0.8000)$ & $(0.6538,0.7523,0.8772)$ & 0.0002 & Safe \\
1.23 & 0.9818 & $(0.7046,0.7810)$ & $(0.6840,0.8021,0.8772)$ & 0.0004 & Safe \\
1.26 & 0.9818 & $(0.7264,0.7620)$ & $(0.7052,0.8424,0.8772)$ & 0.0006 & Safe \\
\hline
\end{tabular}

Table 1: Monetary equilibria with safe and risky assets

Finally, we examine the effect of inflation on the choice of investment. Table 2 summarizes the result with $\pi=1.06$. Comparing the top panels of Tables 1 and 2 , we can see that inflation has a negative effect on cash reserves, leading to a high probability of a banking panic, but a positive effect on the deposit level. Comparing the lower panels of Table 1 and 2, we can see that asset change occurs at $R^{C}=1.20$, switching from the safe to risky as inflation increases. Technically, an increase in the inflation rate shifts the function $\Delta\left(R^{C}, 0.8925\right)$ down slightly, so that the range of parameters for which moral hazard occurs, that is, $\Delta\left(R^{C}, 0.8925\right)<0$, is likely to emerge. Intuitively, because a bank holds more cash with the safe asset than with the risky asset, investing in the safe asset incurs greater inflation costs than investing in the risky asset. However, the effect of inflation on the choice of investment seems to be relatively small because asset change occurs only when $\eta \lambda$ is near the threshold. The reason for this is that with the LLR a bank can avoid money holding cost of higher inflation by investing more in long-term assets and relying more on the discount window for repayments during the day. That is, the effect of inflation is mitigated to some extent by a bank's inflation-avoiding 
behavior. On the other hand, too much reliance on the discount window due to higher inflation rates implies higher threshold values of $R^{C *}$ and $\hat{R}^{C *}$ so that banks tend to use loans even at relatively high lending rates.

\begin{tabular}{|c|c|c|c|c|c|}
\hline$R^{C}$ & $\eta \lambda$ & $\left(z_{R}, d_{R}\right)$ & $\left(\alpha_{R}^{*}, \alpha_{R}^{* *}, \alpha_{R}^{* * *}\right)$ & $\Delta\left(R^{C}, \eta\right)$ & Types of Equilibrium \\
\hline \hline 1.20 & 0.99 & $(0.0183,0.9074)$ & $(0.0173,0.0183,0.8280)$ & -0.0078 & Risky \\
1.23 & 0.99 & $(0.2766,0.8794)$ & $(0.2610,0.2822,0.8280)$ & -0.0046 & Risky \\
1.26 & 0.99 & $(0.4268,0.8537)$ & $(0.4026,0.4435,0.8280)$ & -0.0030 & Risky \\
\hline \hline 1.20 & 0.9818 & $(0.0338,0.8812)$ & $(0.0319,0.0336,0.8004)$ & -0.0004 & Risky \\
1.23 & 0.9818 & $(0.5926,0.8183)$ & $(0.5590,0.6555,0.8772)$ & 0.0006 & Safe \\
1.26 & 0.9818 & $(0.6315,0.8010)$ & $(0.5958,0.7117,0.8772)$ & 0.0009 & Safe \\
\hline
\end{tabular}

Table 2: Monetary equilibria with higher inflation: $\pi=1.06$

\subsection{Discussions}

From our analysis so far, we can summarize the main implications of the economic roles and consequences of the LLR as follows.

(i) The LLR reduces a bank's cash reserves and increases the likelihood of depletion of the liquid reserves (a banking panic). However, the magnitude of a panic is mitigated.

(ii) The LLR may create moral hazard, that is, private banks may take more financial risks in terms of long-term assets.

(iii) The occurrence of moral hazard is determined mainly by the expected relative returns of the safe and risky assets and the cost of holding collateral given the asymmetric information about the quality of a bank's assets that can be used as collateral.

From (i) and (ii), we can conclude that the existence of a credible LLR can make a financial system unstable but it is potentially welfare improving. In this sense, there is a trade-off between efficiency and financial stability. Furthermore, in contrast to conventional wisdom, from (iii), high (penalty) lending rates cannot have much impact on moral hazard when the 
expected return on the risky asset is sufficiently high, the cost of holding collateral is low, and the problem of asymmetric information is severe.

One might think that if the LLR could commit in advance regarding the quality of acceptable collaterals during a crisis, based on its efforts to keep track of banks' portfolio strategies and eliminate asymmetric information about their assets (i.e., audit and stress test), it would increase the banks' incentives to behave prudently. While we admit the significance of efforts for overcoming the asymmetric information problem, there is an important time-inconsistency problem, as discussed in Kydland and Prescott (1977) and Ennis and Keister (2009). The central bank would like banks to believe that it will accept only safe assets (e.g., T-bills) as collateral for the discount window loans during a panic. However, if a panic actually occurred, the central bank would find it optimal to lend liquidity to troubled banks against even their risky assets (e.g., equity shares and mortgage-backed securities). If so, banks will be willing to hold risky assets in advance, and as a result, the lack of commitment leads to moral hazard and banking defaults.

Our results are related to some existing literature on the LLR policy and moral hazard. Martin (2006) shows that a liquidity provision policy by the central bank can prevent panics without creating moral hazard. In his model, which is based on a banking model of Cooper and Ross (1998), risk-averse depositors prefer the safe asset to the risky asset because borrowing strategies and portfolio choices are dichotomized. In contrast, in our model the risky asset has a comparative advantage in borrowing money from the central bank due to limited liability, which gives banks an incentive to choose the risky asset in advance. Repullo (2005) also shows that the existence of the LLR does not increase bank's risk-taking incentives, but simply reduces their liquid reserves. His paper and our paper share a common view that the expected return on the risky asset is the main factor in determining the risk of a bank's portfolio. However, in our model the existence of the LLR still matters since the collateralized LLR lending creates a liquidity premium on illiquid long-term assets.

Finally, we have abstracted from reputation effects by assuming that banks live only for one period and the central bank committee members are replaced in each period. These 
assumptions make the analysis simple and highlight banks' risk-taking investment behavior in the presence of the LLR. If banks lived infinitely and committee members were not renewed, the LLR could use history-dependent lending policies that have a positive effect on banks' incentives for prudent behavior. However, once the LLR adopts the too-big-to-fail doctrine or fail to make a strong commitment, the reputation effect would be weakened so that our analysis still remains relevant.

\section{Extensions}

In this section, we examine some policies to curb moral hazard. As stated earlier, the presence of the LLR improves welfare but decreases financial stability. Though not modelled explicitly here, a government would place more value on financial stability than ex ante efficiency, because a crisis may have significant negative impacts on the real sector (e.g., increasing unemployment, decreasing output, etc.). Can the government eliminate banking defaults or moral hazard at the expense of welfare? To answer this question, we consider two policies that are often implemented in practice: a liquidity requirement and constructive ambiguity.

\subsection{Liquidity Requirement}

Under the liquidity requirement, all banks must hold a certain proportion of liquid reserves in their portfolio. The liquidity coverage ratio is envisioned by Basel III. Specifically, the government forces banks to invest at least a fraction $\kappa \in[0,1]$ of their deposits $d$ in liquid reserves in the $\mathrm{CM}$, so it has to hold that

$$
z \geq \kappa d
$$

The liquidity requirement imposes a lower bound of cash reserves $z$ banks should hold. A higher $\kappa$ implies a tighter constraint for banks.

Suppose now that the liquidity requirement is severe enough to be binding only with the risky asset, but not with the safe asset, that is, $\kappa$ satisfies

$$
\frac{z_{R}}{d_{R}}<\kappa<\frac{z_{S}}{d_{S}}
$$


where $\left(z_{R}, d_{R}\right)$ and $\left(z_{S}, d_{S}\right)$ are the unconstrained equilibrium allocation, obtained in Proposition 1 and 2, respectively, without imposing the liquidity requirement. Remember that the point $\left(z_{S}, d_{S}\right)$ is in the northwestern area of $\left(z_{R}, d_{R}\right)$ in Figure 5 , implying that $\left(z_{R}, d_{R}\right)$ is more likely to be restricted by the requirement. Then, the first order condition of the optimal portfolio choice with risky asset must be

$$
\Phi(z, d) \equiv \frac{1}{\pi} \Phi_{z}(z, d)-R \Phi_{l}(z, d)<0,
$$

with $z=\kappa d$. The Euler equation now becomes, $-1+\beta V^{\prime}(d)=0$ where

$$
V^{\prime}(d)=\frac{\partial z}{\partial d} \frac{\partial V(d)}{\partial z}+\frac{\partial V(d)}{\partial d}=\kappa \Phi(z, d)+R \Phi_{l}(z, d)=\frac{\kappa}{\pi} \Phi_{z}(z, d)+(1-\kappa) R \Phi_{l}(z, d) .
$$

Thus, the solutions with a binding liquidity requirement, denoted by $\left(z_{R}^{\kappa}, d_{R}^{\kappa}\right)$, should satisfy $z_{R}^{\kappa}=\kappa d_{R}^{\kappa}$ where $d_{R}^{\kappa}$ is the unique solution to

$$
\kappa \Phi_{z}(\kappa d, d)+(1-\kappa) \pi R \Phi_{l}(\kappa d, d)=\frac{\pi}{\beta} .
$$

The effects of the liquidity constraint on the optimal values of deposits and cash reserves are summarized as follows.

Proposition 4 The optimal value of $d_{R}^{\kappa}$ is strictly decreasing in $\kappa$. The effect of $\kappa$ on $z_{R}^{\kappa}$ is negative if $\xi$ is sufficiently small, and positive otherwise.

A tighter liquidity requirement (i.e., a higher $\kappa$ ) makes the deposit contract less attractive so that the buyers reduce their deposits. The effect on the reserves is ambiguous because it increases the required reserves but discourages depositing. The proposition shows that the latter effect dominates the former if the degree of relative risk aversion is sufficiently small (the substitution effect is strong) and vice versa.

We now examine the effect of the liquidity requirement on the choice of asset investments. Suppose that $\xi$ is not so small that $z_{R}^{\kappa}$ is strictly increasing in $\kappa$. Then, a gradual increase in $\kappa$ decreases $d_{R}^{\kappa}$ and increases $z_{R}^{\kappa}$, reducing the probability of a panic and welfare. If the expected return on the risky asset is sufficiently high (i.e., $\eta \lambda \approx 1$ ), the risky asset will be adopted 
even when $\frac{z_{R}^{\kappa}}{d_{R}^{\kappa}}=\kappa \approx \frac{z_{S}}{d_{S}}$. On the other hand, the effect of a tighter liquidity requirement is ambiguous. We demonstrate it using numerical examples in which the parameter values are the same as in the top panel of Table 1 , that is, with $\eta=0.9$.

Table 3 compares two situations where the liquidity requirement is slack with $\kappa=0$, and sufficiently tight with $\kappa=\frac{z_{S}}{d_{S}}$. Note that the equilibrium outcomes with $\kappa=0$ are the same as in the top panel of Table 1 . Observe that the safe asset is selected when $R^{C}=1.2$, while the risky asset continues to be selected even in the presence of the liquidity requirement when $R^{C}=1.23$ and 1.26. The liquidity requirement reduces the benefit of the risky asset used as collateral. This result suggests that a proper combination of the liquidity regulation and the lending rate can reduce not only the likelihood of a banking panic but also control the moral hazard problem at the expense of ex-ante welfare.

\begin{tabular}{|c|c|c|c|c|c|}
\hline$R^{C}$ & $\kappa$ & $(z, d)$ & $\left(\alpha^{*}, \alpha^{* *}, \alpha^{* * *}\right)$ & $\Delta\left(R^{C}, \eta\right)$ & Types of Equilibrium \\
\hline \hline 1.20 & 0.0000 & $(0.4082,0.8557)$ & $(0.3963,0.4205,0.8280)$ & -0.0039 & Risky \\
1.23 & 0.0000 & $(0.5578,0.8255)$ & $(0.5416,0.5856,0.8280)$ & -0.0022 & Risky \\
1.26 & 0.0000 & $(0.6432,0.7988)$ & $(0.6245,0.6879,0.8280)$ & -0.0014 & Risky \\
\hline \hline 1.20 & 0.8418 & $(0.6734,0.8000)$ & $(0.6538,0.7523,0.8772)$ & 0.0003 & Safe \\
1.23 & 0.9022 & $(0.7212,0.7994)$ & $(0.7002,0.7571,0.8280)$ & -0.0001 & Risky \\
1.26 & 0.9533 & $(0.7435,0.7799)$ & $(0.7219,0.7952,0.8280)$ & -0.0003 & Risky \\
\hline
\end{tabular}

Table 3: Monetary equilibria with liquidity requirement: $\kappa=\frac{z_{S}}{d_{S}}$

\subsection{Constructive Ambiguity}

Constructive ambiguity is defined as not declaring in advance and being ambiguous about which banks would be regarded as large enough to fail and be rescued. Some economists and policymakers are positive about its effectiveness in controlling the moral hazard problem. For example, Giannini (1999, p.14) states that "the task of curbing moral hazard appears to have been performed largely by constructive ambiguity," while Schwartz (2002, p.452) puts "Constructive ambiguity supposedly constrains excessive risk taking by banks." 6

\footnotetext{
${ }^{6}$ See also Corrigan (1990) and Freixas et al. (2000).
} 
To address this issue, we now consider the LLR policy with constructive ambiguity and assume that discount window lending is available with probability $\rho \in[0,1]$. This probability is known to depositors and banks. Clearly, when $\rho=1$ the analysis is identical to the one given so far, while when $\rho=0$ the model is identical to the basic model without the LLR. We can think of $1-\rho$ as measuring the degree of policy ambiguity and controllable by the central bank.

Suppose that $\rho \in(0,1)$ and consider first the case of the safe asset. Note that the bank's solutions after the realization of $\alpha$ are the same as that in Lemma 2 when the bank has access to the LLR and that in Lemma 3 when the bank does not. Then, the value function at the beginning of a day can be modified as follows:

$$
\begin{aligned}
V_{\rho}(d) & =\max _{0 \leq z \leq d} \rho\left\{\int_{0}^{\alpha^{*}}\left[\alpha u\left(q^{*}\right)+\left(1-\frac{\alpha}{\alpha^{*}}\right) \frac{z}{\pi}\right] f(\alpha) d \alpha+\int_{\alpha^{*}}^{\alpha^{* *}} \alpha u\left(\frac{z}{\alpha \pi}\right) f(\alpha) d \alpha\right. \\
& +\int_{\alpha^{* *}}^{\alpha^{* * *}}\left[\alpha u\left(u^{-1 \prime}\left(R^{C}\right)\right)-R^{C}\left(\alpha u^{-1 \prime}\left(R^{C}\right)-\frac{z}{\pi}\right)\right] f(\alpha) d \alpha \\
& \left.+\int_{\alpha^{* * *}}^{1}\left[\alpha u\left(\frac{\frac{R^{C}}{\pi} z+R(d-z)}{R^{C} \alpha}\right)-R(d-z)\right] f(\alpha) d \alpha\right\} \\
& +(1-\rho)\left\{\int_{0}^{\alpha^{*}}\left[\alpha u\left(q^{*}\right)+\left(1-\frac{\alpha}{\alpha^{*}}\right) \frac{z}{\pi}\right] f(\alpha) d \alpha+\int_{\alpha^{*}}^{1} \alpha u\left(\frac{z}{\alpha \pi}\right) f(\alpha) d \alpha\right\} \\
& +\{1-E(\alpha)\}\left\{u\left(q^{*}\right)-q^{*}\right\}+R(d-z)+T+\max _{x \geq 0}\{U(x)-x\}+\max _{d_{+} \geq 0}\left\{-d_{+}+\beta V\left(d_{+}\right)\right\} .
\end{aligned}
$$

Since a bank has an opportunity to borrow form the LLR with probability $\rho$, the value function is a convex combination of the expected utility with and without access to the LLR with weights $\rho$ and $1-\rho$. The first order condition with respect to $z$ yields

$$
\Psi_{\rho}(z, d) \equiv \rho\left[\frac{1}{\pi} \Psi_{z}(z, d)-R \Psi_{k}(z, d)\right]+(1-\rho)\left[\frac{1}{\pi} \Upsilon(z)-R\right] \geq 0
$$

with equality if $z<d$.

The Euler equation becomes $\beta V_{\rho}^{\prime}(d)=1$ where

$$
V_{\rho}^{\prime}(d)=\frac{\partial z}{\partial d} \frac{\partial V_{\rho}(d)}{\partial z}+\frac{\partial V_{\rho}(d)}{\partial d} .
$$

Thus, an interior solution, denoted by $\left(z_{S}^{\rho}, d_{S}^{\rho}\right)$, must satisfy the Euler equation, $\beta V_{\rho}^{\prime}(d)=$ 
$\beta \frac{\partial V_{\rho}(d)}{\partial d}$ or

$$
\rho \Psi_{k}(z, d)+(1-\rho)=\frac{1}{\beta R}
$$

and the first order condition

$$
\rho \Psi_{z}(z, d)+(1-\rho) \Upsilon(z)=\frac{\pi}{\beta}
$$

The effects of $\rho$ on the equilibrium allocations are characterized in the following proposition.

Proposition 5 The optimal cash reserves $z_{S}^{\rho}$ are decreasing in $\rho$, and the optimal deposits $d_{S}^{\rho}$ are increasing in $\rho$.

This result shows that constructive ambiguity gives banks an incentive to insure themselves by increasing their cash reserves, thus reducing the probability of a banking panic, while the deposit level decreases since the deposit contract becomes less attractive.

We next examine the effect of $\rho$ on the threshold for the activated LLR. Let $R_{\rho}^{C *}$ be defined by $\tilde{\Psi}_{\rho}\left(R_{\rho}^{C *}\right)=0$ where

$$
\begin{aligned}
\tilde{\Psi}_{\rho}\left(R^{C}\right) & \equiv \pi \Psi_{\rho}(d, d)=\rho\left\{\Psi_{z}(d, d)-\pi R \Psi_{k}(d, d)\right\}+(1-\rho)\{\Upsilon(d)-\pi R\} \\
& =\frac{\pi}{\beta}-\pi R\left[\rho\left\{F\left(\alpha^{* * *}\right)+\frac{1}{R^{C}} \int_{\alpha^{* * *}}^{1} u^{\prime}\left(\frac{d}{\alpha \pi}\right) f(\alpha) d \alpha\right\}+(1-\rho)\right] .
\end{aligned}
$$

From this it follows that $R_{\rho}^{C *}$ is increasing in $\rho$ and $R_{\rho}^{C *} \rightarrow R^{C *}$ as $\rho \rightarrow 1$. This result shows that the parameter set $\left(\pi R, R_{\rho}^{C *}\right]$, when the discount window is activated, becomes smaller as $\rho$ decreases, implying that constructive ambiguity (low $\rho$ ) will be inconsistent with a higher (penalty) lending rate. If both the policies were implemented rigorously, banks might stop borrowing from the LLR even when there is a banking panic.

Not surprisingly, similar results are obtained in the case of the risky asset. The proof is quite similar to that of Proposition 5 and hence omitted here (available upon request).

Proposition 6 The optimal cash reserves $z_{R}^{\rho}$ are decreasing in $\rho$, and the optimal deposits $d_{R}^{\rho}$ are increasing in $\rho$. In addition, the threshold, $\hat{R}_{\rho}^{C *}$ is also increasing in $\rho$. 
To illustrate the effect of constructive ambiguity on the choice of investment, we use numerical examples. We compare two regimes, $\rho=0.7$ and $\rho=1$. Notice that the case of $\rho=1$ is identical to the upper panel of Table 1 . Table 4 illustrates that constructive ambiguity gives the banks an incentive to insure themselves by increasing their cash reserves. Thus, by reducing the probability of a banking panic, constructive ambiguity can prevent banks from taking risks. This occurs when $R^{C}=1.2$ and 1.23. Intuitively, since a bank relies more heavily on the discount window with the risky asset than with the safe asset, the ambiguity reduces the value of investing in the risky asset more drastically than in the safe asset. These numerical results imply that constructive ambiguity may be an effective policy tool to curb moral hazard, supporting the view of Giannini and Schwartz, but depositors bear the welfare cost of such a policy.

\begin{tabular}{|c|c|c|c|c|c|}
\hline$R^{C}$ & $\rho$ & $(z, d)$ & $\left(\alpha^{*}, \alpha^{* *}, \alpha^{* * *}\right)$ & $\Delta\left(R^{C}, \eta\right)$ & Types of Equilibrium \\
\hline \hline 1.20 & 1.0 & $(0.4082,0.8557)$ & $(0.3963,0.4205,0.8280)$ & -0.0039 & Risky \\
1.23 & 1.0 & $(0.5578,0.8255)$ & $(0.5416,0.5856,0.8280)$ & -0.0022 & Risky \\
1.26 & 1.0 & $(0.6432,0.7988)$ & $(0.6245,0.6879,0.8280)$ & -0.0014 & Risky \\
\hline \hline 1.20 & 0.7 & $(0.7247,0.7710)$ & $(0.7036,0.8096,0.8553)$ & 0.0004 & Safe \\
1.23 & 0.7 & $(0.7361,0.7537)$ & $(0.7146,0.8380,0.8553)$ & 0.0001 & Safe \\
1.26 & 0.7 & $(0.7244,0.7652)$ & $(0.7033,0.7748,0.8115)$ & -0.0001 & Risky \\
\hline
\end{tabular}

Table 4: Monetary equilibria with constructive ambiguity

Finally, it is worth noting that our results raise an important time-inconsistency problem again. If constructive ambiguity is effective, the central bank would like banks to believe that they cannot be certain if they will be rescued during a panic. However, if a panic occurred, the central bank would find it optimal to provide liquidity to troubled banks even in a state where it should not. If so, banks will believe that they will be rescued for sure during a panic ex ante, ending up making this policy ineffective. Constructive ambiguity requires a strong commitment to future actions of the LLR. 


\section{Conclusion}

We developed a monetary model of banking panics that allows us to investigate the economic role and consequence of the lender of last resort. Given that private banks operate subject to limited liability, collateralized assets have liquidity values so that cash and long-term assets become substitutes during panics in the presence of the LLR. We showed that the LLR's liquidity provision will diminish banks' incentive to hold liquid assets, which in turn increases the probability of a banking panic. Despite this unpleasant side effect, the LLR will mitigate the loss from banking panics and is beneficial. We also showed limited liability frees them from their payment responsibility in case of a default; hence, private banks can be induced to invest in risky assets rather than safe assets. That is, the LLR can create moral hazard in investment where private banks take more financial risk in terms of long-term assets.

Our results point to the public debate on the classical doctrine versus the moral hazard problem. To the best of our knowledge, our paper is the first to consider the effect of the LLR's liquidity provision to influence banks' portfolio decision, which eventually increases the ex ante probability of banking panics, and causes the moral hazard problem that increases financial risks in long-term assets. We have done this in a monetary framework where the role of liquidity is made explicit in the occurrence of a banking panic. Our results are negative about the conventional view that a high rate on the discount window can prevent banks from taking excessive risks. Additional policies such as liquidity requirements and constructive ambiguity can give banks self-guarding incentives and increase cash reserves, reducing the likelihood of a shortage of reserves, and in addition can influence the choice of investments.

The next step would be to use our model to evaluate the impact of a capital requirement on the choice of investments as discussed in Repullo (2004, 2005). This issue could be addressed by adding risk-neutral investors who provide equity capital to the banks. Another possibility would be to extend our model to an open economy to assess the need of an international LLR. 


\section{Appendix}

\section{Proof of Lemma 1}

The first order condition with respect to $\theta$ is as follows:

$$
\frac{z}{\pi}\left\{u^{\prime}\left(\frac{\theta z}{\alpha \pi}\right)-1\right\} \geq 0
$$

with equality if $\theta<1$. There are two possible cases for the solution. If $\theta<1$, then $u^{\prime}\left(q^{n}\right)=$ $1 \Leftrightarrow q^{n}=q^{*}$. This case is true when $\theta=\frac{\alpha \pi q^{*}}{z}<1 \Leftrightarrow \alpha<\frac{z}{\pi q^{*}} \equiv \alpha^{*}$. If $\theta=1$, then $u^{\prime}\left(q^{n}\right) \geq 1 \Leftrightarrow q^{n}=\frac{z}{\alpha \pi} \leq q^{*}$, leading to $\alpha \geq \alpha^{*}$. The lemma follows.

\section{Proof of Lemma 2}

Applying the optimal payment plan $q^{n}=\min \left\{\frac{z}{\alpha \pi}, q^{*}\right\}$ and $\theta=\min \left\{\frac{\alpha}{\alpha^{*}}, 1\right\}$ with the critical value $\alpha^{*}=\frac{z}{\pi q^{*}}$ described in Lemma 1 , the value function in the $\mathrm{CM}, W(\cdot)$, and the balance sheet constraint, $d=z+k+l$, the banks' portfolio choice problem can be written as

$$
\begin{aligned}
V(d)= & \max _{z, k, l \geq 0} \int_{0}^{1}\left[\alpha\left\{u\left(q^{n}\right)+W(0, k, l, 0)\right\}+(1-\alpha)\left\{u\left(q^{*}\right)+W\left(\frac{(1-\theta) z}{(1-\alpha) \pi}, k, l, q^{*}\right)\right\}\right] f(\alpha) d \alpha, \\
= & \max _{z, l \geq 0} \int_{0}^{\frac{z}{\pi q^{*}}}\left[u\left(q^{*}\right)-(1-\alpha) q^{*}+\left(1-\frac{\alpha \pi q^{*}}{z}\right) \frac{z}{\pi}\right] f(\alpha) d \alpha \\
& +\int_{\frac{z}{\pi q^{*}}}^{1}\left[\alpha u\left(\frac{z}{\alpha \pi}\right)+(1-\alpha)\left\{u\left(q^{*}\right)-q^{*}\right\}\right] f(\alpha) d \alpha \\
& +R[(d-z-l)+\eta \lambda l]+T+\max _{x \geq 0}\{U(x)-x\}+\max _{d_{+} \geq 0}\left\{-d_{+}+\beta V\left(d_{+}\right)\right\} .
\end{aligned}
$$

The first order conditions yield $l=0($ since $\eta \lambda<1)$ and

$$
\frac{1}{\pi} \Upsilon(z) \equiv \frac{1}{\pi}\left[F\left(\alpha^{*}\right)+\int_{\alpha^{*}}^{1} u^{\prime}\left(q^{n}\right) f(\alpha) d \alpha\right] \geq R,
$$

with equality if $\Upsilon(d)<\pi R$. Since

$$
\Upsilon^{\prime}(z)=\int_{\alpha^{*}}^{1} \frac{1}{\alpha \pi} u^{\prime \prime}\left(q^{n}\right) f(\alpha) d \alpha<0
$$

and $\Upsilon(0)=+\infty>\pi R$, there exists a unique solution $z=z(d) \in(0, d)$ to $\Upsilon(z(d))=\pi R$, if $\Upsilon(d)<\pi R$. Otherwise, $\Upsilon(d) \geq \pi R$ for all $z \in(0, d]$ and so we must have a corner solution, $z=d$. The quantity of long-term safe assets is given by $k=d-z \geq 0$. 


\section{Proof of Theorem 1}

The Euler equation is

$$
-1+\beta V^{\prime}(d)=0
$$

where

$$
V^{\prime}(d)=\frac{\partial z}{\partial d} \frac{\partial V(d)}{\partial z}+\frac{\partial V(d)}{\partial d} .
$$

There are two cases. For $d \geq \Upsilon^{-1}(\pi R)$ we have $z=z(d) \in(0, d)$ (an interior solution) and $\Upsilon(z(d))=\pi R$, which implies

$$
V^{\prime}(d)=\frac{\partial V(d)}{\partial d}=R
$$

and, thus, the Euler equation is $-1+\beta R=0$, which is impossible under our assumption $\beta R<1$. Hence, $d \geq \Upsilon^{-1}(\pi R)$ with $z=z(d) \in(0, d)$ (an interior solution) cannot be an equilibrium.

For $d<\Upsilon^{-1}(\pi R)$, we have $z=d$ (the corner solution), and so the Euler equation is $-1+\beta V^{\prime}(d)=-1+\beta\left[\left\{\frac{1}{\pi} \Upsilon(d)-R\right\}+R\right]=0$ or

$$
\frac{\pi}{\beta}=F\left(\frac{d}{\pi q^{*}}\right)+\int_{\frac{d}{\pi q^{*}}}^{1} u^{\prime}\left(\frac{d}{\pi \alpha}\right) f(\alpha) d \alpha \quad(=\Upsilon(d)),
$$

where the R.H.S. is the marginal value of cash holdings at $z=d$. It satisfies: $\Upsilon(0)=$ $\infty>\frac{\pi}{\beta}>1=\Upsilon\left(\pi q^{*}\right)$ and $\Upsilon^{\prime}(\cdot)<0$ (see above). Hence, there exists a unique solution $d \in\left(0, \pi q^{*}\right)$ to (A.1). Since $d<\pi q^{*}$ implies $\alpha^{*}<1$, the probability of banking panics is positive, $1-F\left(\alpha^{*}\right) \in(0,1)$, in equilibrium.

\section{Proof of Corollary 1}

Differentiating (A.1) with respect to $\pi$ and using (A.1) yields

$$
\frac{\partial d_{N}}{\partial \pi}=\frac{\frac{1}{\beta}+\frac{1}{\pi} \int_{\frac{d_{N}}{\pi q^{*}}}^{1} u^{\prime \prime}\left(\frac{d_{N}}{\pi \alpha}\right) \frac{d_{N}}{\alpha \pi} f(\alpha) d \alpha}{\int_{\frac{d_{N}}{\pi q^{*}}}^{1} u^{\prime \prime}\left(\frac{d_{N}}{\pi \alpha}\right) \frac{f(\alpha)}{\alpha \pi} d \alpha}=-\frac{\frac{1}{\beta}-\frac{\xi}{\pi}\left\{\frac{\pi}{\beta}-F\left(\frac{d_{N}}{\pi q^{*}}\right)\right\}}{\frac{\xi}{d_{N}} \int_{\frac{d_{N}}{\pi q^{*}}}^{1} u^{\prime}\left(\frac{d_{N}}{\pi \alpha}\right) f(\alpha) d \alpha}<0
$$

if $\xi<\hat{\xi} \equiv \frac{\frac{\pi}{\beta}}{\frac{\pi}{\beta}-F\left(\frac{d_{N}}{\pi q^{*}}\right)}$. Clearly, if $\xi<\hat{\xi}, \alpha^{*}=\frac{d_{N}}{\pi q^{*}}$ is decreasing in $\pi$, it implies that $1-F\left(\alpha^{*}\right)$ is increasing in $\pi$. 


\section{Proof of Lemma 3}

We have the following system of equations induced by the first order conditions:

$$
\begin{aligned}
u^{\prime}\left(\frac{\theta z}{\alpha \pi}+\frac{b}{\alpha}\right)-1 & =\frac{\mu \pi}{z}, \\
u^{\prime}\left(\frac{\theta z}{\alpha \pi}+\frac{b}{\alpha}\right)-R^{C}\left(1+\mu_{k}\right) & =-\mu_{b},
\end{aligned}
$$

where $\mu \geq 0$ is the Lagrange multiplier of $\theta \leq 1, \mu_{b} \geq 0$ is the Lagrange multiplier of the nonnegativity constraint $b \geq 0$, and $\mu_{k} \geq 0$ is the Lagrange multiplier of the borrowing constraint (4), $R^{C} b \leq R k$.

There are four cases for the solution to the above equations (A.3) and (A.4).

Case 1: $\theta<1$ and $b=0$. Since $\theta<1$ implies $\mu=0$, we have in (A.3),

$$
u^{\prime}\left(\frac{\theta z}{\alpha \pi}+\frac{b}{\alpha}\right)=1 \text {. }
$$

This implies in (A.4) that we must have $\mu_{b}>0$, leading to $b=0$. Note that $b=0$ and $u^{\prime}\left(q^{n}\right)=1$ further lead to

$$
\theta=\frac{\alpha \pi q^{*}}{z}
$$

and $\theta<1 \Longleftrightarrow \alpha<\alpha^{*} \equiv \frac{z}{\pi q^{*}}$. Hence, for $\alpha \in\left(0, \alpha^{*}\right)$, the solution is $\theta<1$ and $b=0$.

Case 2: $\theta=1$ and $b=0 . \quad \theta=1$ and $b=0$ lead to $\mu \geq 0, \mu_{k}=0$, and $\mu_{b} \geq 0$, which yield

$$
\begin{aligned}
& u^{\prime}\left(\frac{z}{\alpha \pi}\right) \geq 1 \quad \Longleftrightarrow \alpha \geq \alpha^{*}, \\
& u^{\prime}\left(\frac{z}{\alpha \pi}\right) \leq R^{C} \Longleftrightarrow \alpha \leq \alpha^{* *},
\end{aligned}
$$

where $\alpha^{* *} \equiv \frac{z}{\pi u^{-1 \prime}\left(R^{C}\right)}>\frac{z}{\pi q^{*}} \equiv \alpha^{*}$ with $R^{C}>1$. Hence, for $\alpha \in\left[\alpha^{*}, \alpha^{* *}\right]$, the solution is $\theta=1$ and $b=0$.

Case 3: $\theta=1$ and $b \in\left(0, \frac{R k}{R^{C}}\right) . \mu_{k}=0$ and $\mu_{b}=0$ lead to

$$
u^{\prime}\left(\frac{z}{\alpha \pi}+\frac{b}{\alpha}\right)=R^{C} \Longleftrightarrow b=\alpha u^{-1 \prime}\left(R^{C}\right)-\frac{z}{\pi} .
$$

This implies that $b>0 \Longleftrightarrow \alpha>\alpha^{* *} \equiv \frac{z}{\pi u^{-1{ }^{\prime}\left(R^{C}\right)}}$ and $R^{C} b<R k \Longleftrightarrow \alpha<\alpha^{* * *} \equiv \frac{\frac{R^{C}}{\pi} z+R k}{R^{C} u^{-1 \prime}\left(R^{C}\right)}$. Hence, for $\alpha \in\left(\alpha^{* *}, \alpha^{* * *}\right)$, the solution is $\theta=1$ and $b \in\left(0, \frac{R k}{R^{C}}\right)$.

Case 4: $\theta=1$ and $b=\frac{R k}{R^{C}} \cdot R^{C} b=R k$ leads to $\mu_{k} \geq 0$ and $\mu_{b}=0$, which yield

$$
u^{\prime}\left(\frac{z}{\alpha \pi}+\frac{R k}{\alpha R^{C}}\right) \geq R^{C} \Longleftrightarrow \alpha \geq \alpha^{* * *} \equiv \frac{\frac{R^{C}}{\pi} z+R k}{R^{C} u^{-1 \prime}\left(R^{C}\right)} .
$$

Hence, for $\alpha \in\left[\alpha^{* * *}, 1\right)$, the solution is $\theta=1$ and $b=\frac{R k}{R^{C}}$.

The above covers all the possible cases and completes the proof. 


\section{Proof of Proposition 1}

First, we identify the parameter space in which $k=d-z>0$. In the first order condition (6), observe that

$$
\Psi(0, d)=\left(\frac{R^{C}}{\pi}-R\right)\left[F\left(\left.\alpha^{* * *}\right|_{z=0}\right)+\frac{1}{R^{C}} \int_{\left.\alpha^{* * *}\right|_{z=0}}^{1} u^{\prime}\left(\frac{R d}{R^{C} \alpha}\right) f(\alpha) d \alpha\right]=\frac{1}{\beta R}\left(\frac{R^{C}}{\pi}-R\right)>0,
$$

where $\left.\alpha^{* * *}\right|_{z=0} \equiv \frac{R d}{R^{C} u^{-1 \prime}\left(R^{C}\right)}$, and the last expression uses the Euler equation (7). Differentiating (6) with respect to $z$ yields

$$
\pi \frac{\partial \Psi(z, d)}{\partial z}=\int_{\alpha^{*}}^{\alpha^{* *}} \frac{1}{\alpha \pi} u^{\prime \prime}\left(\frac{z}{\alpha \pi}\right) f(\alpha) d \alpha+\left(1-\frac{\pi R}{R^{C}}\right) \int_{\alpha^{* * *}}^{1} \frac{\frac{R^{C}}{\pi}-R}{R^{C} \alpha} u^{\prime \prime}\left(\frac{\frac{R^{C}}{\pi} z+R(d-z)}{R^{C} \alpha}\right) f(\alpha) d \alpha<0 .
$$

Further, evaluating (6) at $z=d$ and $d>0$ satisfying (3), we have:

$$
\begin{aligned}
\pi \Psi(d, d) & =F\left(\left.\alpha^{*}\right|_{z=d}\right)+\int_{\left.\alpha^{*}\right|_{z=d}}^{1} u^{\prime}\left(\frac{d_{N}}{\pi \alpha}\right) f(\alpha) d \alpha-\pi R\left[F\left(\left.\alpha^{* * *}\right|_{z=d}\right)+\frac{1}{R^{C}} \int_{\left.\alpha^{* * *}\right|_{z=d}}^{1} u^{\prime}\left(\frac{d_{N}}{\pi \alpha}\right) f(\alpha) d \alpha\right] \\
& =\frac{\pi}{\beta}-\pi R\left[F\left(\left.\alpha^{* * *}\right|_{z=d}\right)+\frac{1}{R^{C}} \int_{\left.\alpha^{* * *}\right|_{z=d}}^{1} u^{\prime}\left(\frac{d_{N}}{\pi \alpha}\right) f(\alpha) d \alpha\right] \\
& \equiv \tilde{\Psi}\left(R^{C}\right),
\end{aligned}
$$

where $\left.\alpha^{*}\right|_{z=d}=\frac{d_{N}}{\pi q^{*}},\left.\alpha^{* * *}\right|_{z=d}=\frac{d_{N}}{\pi u^{-1}\left(R^{C}\right)}$ and $d_{N}=z_{N}$ is the equilibrium deposit without the LLR as described in Theorem 1. In the last expression, we have:

$$
\tilde{\Psi}\left(R^{C}\right) \rightarrow \frac{\pi}{\beta}-\pi R\left[F\left(\left.\alpha^{* * *}\right|_{z=d}\right)+\frac{1}{\pi R} \int_{\left.\alpha^{* * *}\right|_{z=d}}^{1} u^{\prime}\left(\frac{d_{N}}{\pi \alpha}\right) f(\alpha) d \alpha\right]<0
$$

as $R^{C} \rightarrow \pi R$, since the above term goes to zero as $R \rightarrow \frac{1}{\pi}$ and is decreasing in $R$; $\tilde{\Psi}\left(R^{C}\right)=$ $\frac{\pi}{\beta}-\pi R>0$ for $R^{C} \geq u^{\prime}\left(\frac{d_{N}}{\pi}\right)$ satisfying $\left.\alpha^{* * *}\right|_{z=d}=\min \left\{\frac{d_{N}}{\pi u^{-1 /(}\left(R^{C}\right)}, 1\right\}=1 ;$

$$
\tilde{\Psi}^{\prime}\left(R^{C}\right)=\frac{\pi R}{\left(R^{C}\right)^{2}} \int_{\left.\alpha^{* * *}\right|_{z=d}}^{1} u^{\prime}\left(\frac{d_{N}}{\pi \alpha}\right) f(\alpha) d \alpha>0
$$

Hence there exists a unique critical value, denoted by $R^{C *} \in\left(\pi R, u^{\prime}\left(\frac{d_{N}}{\pi}\right)\right)$ satisfying $\tilde{\Psi}\left(R^{C *}\right)=$ $0, \tilde{\Psi}\left(R^{C}\right)>0$ for $R^{C}>R^{C *}$ and $\tilde{\Psi}\left(R^{C}\right)<0$ for $R^{C}<R^{C *}$. We showed that $z=d$ for $R^{C} \geq R^{C *}$, hence, the solution has to be an interior one if $z<d$ for $R^{C}<R^{C *}$ (if it exists).

We now show the existence and uniqueness of an equilibrium solution $\left(z_{S}, d_{S}\right)>0$ given $R^{C} \in\left(\max \{\pi R, 1\}, R^{C *}\right)$. 
The solution has to satisfy the following system of equations:

$$
\begin{gathered}
\Psi_{z}(z, d) \equiv F\left(\alpha^{*}\right)+\int_{\alpha^{*}}^{\alpha^{* *}} u^{\prime}\left(\frac{z}{\alpha \pi}\right) f(\alpha) d \alpha+\left[F\left(\alpha^{* * *}\right)-F\left(\alpha^{* *}\right)\right] R^{C} \\
+\int_{\alpha^{* * *}}^{1} u^{\prime}\left(\frac{\frac{R^{C}}{\pi} z+R(d-z)}{R^{C} \alpha}\right) f(\alpha) d \alpha=\frac{\pi}{\beta} \\
\Psi_{k}(z, d) \equiv F\left(\alpha^{* * *}\right)+\frac{1}{R^{C}} \int_{\alpha^{* * *}}^{1} u^{\prime}\left(\frac{\frac{R^{C}}{\pi} z+R(d-z)}{R^{C} \alpha}\right) f(\alpha) d \alpha=\frac{1}{\beta R} .
\end{gathered}
$$

Observe that:

$$
\begin{aligned}
& \frac{\partial \Psi_{z}(z, d)}{\partial z}=\int_{\alpha^{*}}^{\alpha^{* *}} \frac{1}{\alpha \pi} u^{\prime \prime}\left(\frac{z}{\alpha \pi}\right) f(\alpha) d \alpha+\int_{\alpha^{* * *}}^{1} \frac{\frac{R^{C}}{\pi}-R}{R^{C} \alpha} u^{\prime \prime}\left(\frac{\frac{R^{C}}{\pi} z+R(d-z)}{R^{C} \alpha}\right) f(\alpha) d \alpha<0 \\
& \frac{\partial \Psi_{z}(z, d)}{\partial d}=\int_{\alpha^{* * *}}^{1} \frac{R}{R^{C} \alpha} u^{\prime \prime}\left(\frac{\frac{R^{C}}{\pi} z+R(d-z)}{R^{C} \alpha}\right) f(\alpha) d \alpha<0
\end{aligned}
$$

$\Psi_{z}\left(z_{N}, d_{N}\right)=\frac{\pi}{\beta} ; \Psi_{z}(\underline{z}, d)=\frac{\pi}{\beta}$ for sufficiently high values of $d$ such that $\alpha^{* * *}=\min \left\{\frac{\frac{R^{C}}{\pi} z+R(d-z)}{R^{C} u^{-1 \prime}\left(R^{C}\right)}, 1\right\}=$ 1 with some lower bound $\underline{z} \in\left(0, z_{N}\right)$. Hence, the implicit equation (A.6) determines a function $z=z(d)$ that satisfies $z^{\prime}(d)<0, z\left(d_{N}\right)=z_{N}$ and $z(d)=\underline{z}>0$ at some $d \in\left(d_{N}, \infty\right)$ that leads to $\alpha^{* * *}=1$.

Observe also that

$$
\begin{aligned}
& \frac{\partial \Psi_{k}(z, d)}{\partial z}=\frac{1}{R^{C}} \int_{\alpha^{* * *}}^{1} \frac{\frac{R^{C}}{\pi}-R}{R^{C} \alpha} u^{\prime \prime}\left(\frac{\frac{R^{C}}{\pi} z+R(d-z)}{R^{C} \alpha}\right) f(\alpha) d \alpha<0 ; \\
& \frac{\partial \Psi_{k}(z, d)}{\partial d}=\frac{1}{R^{C}} \int_{\alpha^{* * *}}^{1} \frac{R}{R^{C} \alpha} u^{\prime \prime}\left(\frac{\frac{R^{C}}{\pi} z+R(d-z)}{R^{C} \alpha}\right) f(\alpha) d \alpha<0 .
\end{aligned}
$$

Further,

$$
\Psi_{k}(d, d)=F\left(\left.\alpha^{* * *}\right|_{z=d}\right)+\frac{1}{R^{C}} \int_{\left.\alpha^{* * *}\right|_{z=d}}^{1} u^{\prime}\left(\frac{d_{N}}{\pi \alpha}\right) f(\alpha) d \alpha>\frac{1}{\beta R}
$$

for $R^{C}<R^{C *}$ and $d=d_{N}$ (satisfying (3)). In this expression, since $\Psi_{k}(d, d)$ is decreasing in all $d>d_{N}$, we must have $\Psi_{k}(d, d)=\frac{1}{\beta R}$ (i.e., condition (A.7) holds true with $z=d$ ) for $R^{C}<R^{C *}$ only when $d>d_{N}$. Finally, since $\frac{1}{\beta R}>1$, it is impossible to hold the condition (A.7) for values

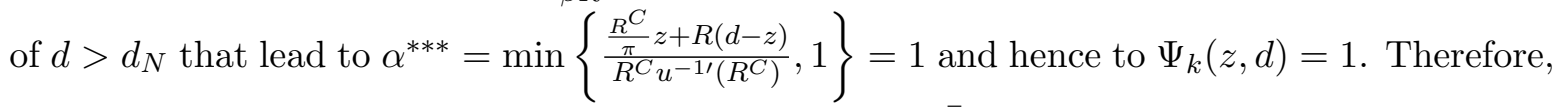
we must necessarily have $z=0$ at some upper bound $\bar{d} \in\left(d_{N}, \infty\right)$, and so condition (A.7) holds true only when $d \in\left(d_{N}, \bar{d}\right]$. Hence, the implicit equation (A.7) determines a function $\tilde{z}=\tilde{z}(d)$ that satisfies $\tilde{z}^{\prime}(d)<0, \tilde{z}(d)=d$ at some $d>d_{N}$ and $\tilde{z}(\bar{d})=0$. 
Combining the above analysis, with some low $d \in\left(d_{N}, \bar{d}\right)$, we have $\tilde{z}(d)=d>z(d)$, while with $d=\bar{d}$, we have $\tilde{z}(\bar{d})=0<z(\bar{d})$. Further,

$$
\frac{\partial}{\partial d}[\tilde{z}(d)-z(d)]=-\frac{\int_{\alpha^{*}}^{\alpha^{* *}} \frac{1}{\alpha \pi} u^{\prime \prime}\left(\frac{z}{\alpha \pi}\right) f(\alpha) d \alpha \times \frac{\partial \Psi_{z}}{\partial d}}{\int_{\alpha^{* * *}}^{1} \frac{\frac{R}{\pi}}{R^{C} \alpha} u^{\prime \prime}\left(\frac{\frac{R^{C}}{\pi} z+R(d-z)}{R^{C} \alpha}\right) f(\alpha) d \alpha \times \frac{\partial \Psi_{z}}{\partial z}}<0 .
$$

Therefore, the two curves, $z=z(d)$ and $\tilde{z}=\tilde{z}(d)$, must intersect once, at $d \in\left(d_{N}, \bar{d}\right)$ and $z \in\left(\underline{z}, z_{N}\right)$, implying that there exists a unique solution to (A.6) and (A.7).

\section{Proof of Corollary 2}

The claim follows from $z_{S} \leq z_{N}$ and $d_{S} \geq d_{N}$.

\section{Proof of Corollary 3}

Remember that the solutions satisfy equations (A.6) and (A.7). Observe that

$$
\begin{aligned}
& \frac{\partial \Psi_{z}\left(z, d ; \pi, R^{C}\right)}{\partial \pi}=-\int_{\alpha^{*}}^{\alpha^{* *}} \frac{z}{\alpha \pi^{2}} u^{\prime \prime}\left(\frac{z}{\alpha \pi}\right) f(\alpha) d \alpha-\int_{\alpha^{* * *}}^{1} \frac{z}{\alpha \pi^{2}} u^{\prime \prime}\left(\frac{\frac{R^{C}}{\pi} z+R(d-z)}{R^{C} \alpha}\right) f(\alpha) d \alpha>0 \\
& \frac{\partial \Psi_{z}\left(z, d ; \pi, R^{C}\right)}{\partial R^{C}}=\left[F\left(\alpha^{* * *}\right)-F\left(\alpha^{* *}\right)\right]-\int_{\alpha^{* * *}}^{1} u^{\prime \prime}\left(\frac{\frac{R^{C}}{\pi} z+R(d-z)}{R^{C} \alpha}\right) \frac{R(d-z)}{\left(R^{C}\right)^{2} \alpha} f(\alpha) d \alpha>0 ; \\
& \frac{\partial \Psi_{k}\left(z, d ; \pi, R^{C}\right)}{\partial \pi}=-\frac{1}{R^{C}} \int_{\alpha^{* * *}}^{1} \frac{z}{\alpha \pi^{2}} u^{\prime \prime}\left(\frac{\frac{R^{C}}{\pi} z+R(d-z)}{R^{C} \alpha}\right) f(\alpha) d \alpha>0 \\
& \frac{\partial \Psi_{k}\left(z, d ; \pi, R^{C}\right)}{\partial R^{C}}=\frac{1}{\left(R^{C}\right)^{2}}\left(-1+\frac{R(d-z) \xi}{\frac{R^{C}}{\pi} z+R(d-z)}\right) \int_{\alpha^{* * *}}^{1} u^{\prime}\left(\frac{\frac{R^{C}}{\pi} z+R(d-z)}{R^{C} \alpha}\right) f(\alpha) d \alpha .
\end{aligned}
$$

These implicit equations determine two continuous and differentiable functions $d=d_{S}\left(\pi, R^{C}\right)$ and $z=z_{S}\left(\pi, R^{C}\right)$ which are characterized as follows:

$$
\begin{aligned}
\left(\begin{array}{c}
\frac{\partial z_{S}}{\partial \pi} \\
\frac{\partial d_{S}}{\partial \pi}
\end{array}\right) & =-\left(\begin{array}{ll}
\frac{\partial \Psi_{k}}{\partial z} & \frac{\partial \Psi_{k}}{\partial d} \\
\frac{\partial \Psi_{z}}{\partial z} & \frac{\partial \Psi_{z}}{\partial d}
\end{array}\right)^{-1}\left(\begin{array}{c}
\frac{\partial \Psi_{k}}{\partial \pi} \\
\frac{\partial \Psi_{z}}{\partial \pi}-\frac{1}{\beta}
\end{array}\right) \\
& =-\frac{1}{\Lambda}\left(\begin{array}{cc}
\frac{\partial \Psi_{z}}{\partial d} & -\frac{\partial \Psi_{k}}{\partial d} \\
-\frac{\partial \Psi_{z}}{\partial z} & \frac{\partial \Psi_{k}}{\partial z}
\end{array}\right)\left(\begin{array}{c}
\frac{\partial \Psi_{k}}{\partial \pi} \\
\frac{\partial \Psi_{z}}{\partial \pi}-\frac{1}{\beta}
\end{array}\right) \\
\left(\begin{array}{c}
\frac{\partial z_{S}}{\partial R^{C}} \\
\frac{\partial d_{S}}{\partial R^{C}}
\end{array}\right) & =-\frac{1}{\Lambda}\left(\begin{array}{cc}
\frac{\partial \Psi_{z}}{\partial d} & -\frac{\partial \Psi_{k}}{\partial d} \\
-\frac{\partial \Psi_{z}}{\partial z} & \frac{\partial \Psi_{k}}{\partial z}
\end{array}\right)\left(\begin{array}{l}
\frac{\partial \Psi_{k}}{\partial R^{C}} \\
\frac{\partial \Psi_{z}}{\partial R^{C}}
\end{array}\right)
\end{aligned}
$$


where

$$
\begin{aligned}
\Lambda & \equiv \operatorname{det}\left(\begin{array}{cc}
\frac{\partial \Psi_{k}}{\partial z} & \frac{\partial \Psi_{k}}{\partial d} \\
\frac{\partial \Psi_{z}}{\partial z} & \frac{\partial \Psi_{z}}{\partial d}
\end{array}\right)=\frac{\partial \Psi_{k}}{\partial z} \frac{\partial \Psi_{z}}{\partial d}-\frac{\partial \Psi_{k}}{\partial d} \frac{\partial \Psi_{z}}{\partial z} \\
& =\frac{\xi}{R^{C} z}\left[\int_{\alpha^{*}}^{\alpha^{* *}} u^{\prime}\left(\frac{z}{\alpha \pi}\right) f(\alpha) d \alpha\right]\left[\int_{\alpha^{* * *}}^{1} \frac{R}{\alpha R^{C}} u^{\prime \prime}\left(\frac{\frac{R^{C}}{\pi} z+R(d-z)}{R^{C} \alpha}\right) f(\alpha) d \alpha\right]<0
\end{aligned}
$$

using (A.8)-(A.11).

$\bigodot$ The effect of $\pi$ on $z_{S}$. Now, inserting (A.9), (A.11), (A.12), and (A.14) into (A.16) and rearranging, we get

$$
\begin{aligned}
\Lambda \frac{\partial z_{S}}{\partial \pi} & =-\frac{\partial \Psi_{z}}{\partial d} \frac{\partial \Psi_{k}}{\partial \pi}+\frac{\partial \Psi_{k}}{\partial d}\left(\frac{\partial \Psi_{z}}{\partial \pi}-\frac{1}{\beta}\right) \\
& =\frac{1}{\pi R^{C}}\left[\int_{\alpha^{* * *}}^{1} \frac{R}{R^{C} \alpha} u^{\prime \prime}\left(\frac{\frac{R^{C}}{\pi} z+R(d-z)}{R^{C} \alpha}\right) f(\alpha) d \alpha\right]\left[\xi \int_{\alpha^{*}}^{\alpha^{* *}} u^{\prime}\left(\frac{z}{\alpha \pi}\right) f(\alpha) d \alpha-\frac{\pi}{\beta}\right]>0
\end{aligned}
$$

if $\xi<\check{\xi} \equiv \frac{\frac{\pi}{\beta}}{\int_{\alpha^{*}}^{\alpha^{* *}} u^{\prime}\left(\frac{z}{\alpha \pi}\right) f(\alpha) d \alpha}$. Since $\Lambda<0$, we have, if $\xi<\check{\xi}$,

$$
\frac{\partial z_{S}}{\partial \pi}<0
$$

In addition, we will make use of the following result.

$$
\begin{aligned}
\frac{\pi}{z} \frac{\partial z_{S}}{\partial \pi}-1 & =\frac{1}{\xi \int_{\alpha^{*}}^{\alpha^{* *}} u^{\prime}\left(\frac{z}{\alpha \pi}\right) f(\alpha) d \alpha}\left[(\xi-1) \int_{\alpha^{*}}^{\alpha^{* *}} u^{\prime}\left(\frac{z}{\alpha \pi}\right) f(\alpha) d \alpha-F\left(\alpha^{*}\right)\right. \\
& \left.-\left[F\left(\alpha^{* * *}\right)-F\left(\alpha^{* *}\right)\right] R^{C}-\int_{\alpha^{* * *}}^{1} u^{\prime}\left(\frac{\frac{R^{C}}{\pi} z+R(d-z)}{R^{C} \alpha}\right) f(\alpha) d \alpha\right]-1 \\
& =-\frac{\frac{\pi}{\beta}}{\xi \int_{\alpha^{*}}^{\alpha^{* *}} u^{\prime}\left(\frac{z}{\alpha \pi}\right) f(\alpha) d \alpha}<0 .
\end{aligned}
$$

The last equality follows from the first order condition (8).

$\bigodot$ The effect of $\pi$ on $d_{S}$. Similarly, inserting (A.8), (A.10), (A.12), and (A.14) into (A.16), using the first oder condition (8), and rearranging terms, we have

$$
\begin{aligned}
\Lambda \frac{\partial d_{S}}{\partial \pi} & =\frac{\partial \Psi_{z}}{\partial z} \frac{\partial \Psi_{k}}{\partial \pi}-\frac{\partial \Psi_{k}}{\partial z}\left(\frac{\partial \Psi_{z}}{\partial \pi}-\frac{1}{\beta}\right) \\
& =\left[\int_{\alpha^{* * *}}^{1} \frac{1}{R^{C} \pi \alpha} u^{\prime \prime}\left(\frac{\frac{R^{C}}{\pi} z+R(d-z)}{R^{C} \alpha}\right) f(\alpha) d \alpha\right]\left[\frac{\xi R}{R^{C}} \int_{\alpha^{*}}^{\alpha^{* *}} u^{\prime}\left(\frac{z}{\alpha \pi}\right) f(\alpha) d \alpha+\frac{\frac{R^{C}}{\pi}-R}{R^{C}} \frac{\pi}{\beta}\right]<0 .
\end{aligned}
$$

Since $\Lambda<0$, we obtain

$$
\frac{\partial d_{S}}{\partial \pi}>0
$$


In addition, we will make use of the following result later.

$$
\Lambda\left(\frac{\partial d_{S}}{\partial \pi}-\frac{\partial z_{S}}{\partial \pi}\right)=\frac{1}{\pi \beta R}\left[\int_{\alpha^{* * *}}^{1} \frac{R}{\alpha R^{C}} u^{\prime \prime}\left(\frac{\frac{R^{C}}{\pi} z+R(d-z)}{R^{C} \alpha}\right) f(\alpha) d \alpha\right]<0,
$$

which leads to

$$
R\left(\frac{\partial d_{S}}{\partial \pi}-\frac{\partial z_{S}}{\partial \pi}\right)=\frac{\frac{R^{C} z}{\pi \beta}}{\xi \int_{\alpha^{*}}^{\alpha^{* *}} u^{\prime}\left(\frac{z}{\alpha \pi}\right) f(\alpha) d \alpha}>0 .
$$

Thus, using the above results, we have

$$
\begin{aligned}
\frac{\partial \alpha^{*}}{\partial \pi} & =\frac{\pi \frac{\partial z}{\partial \pi}-z}{(\pi)^{2} q^{*}}<0, \\
\frac{\partial \alpha^{* *}}{\partial \pi} & =\frac{\pi \frac{\partial z}{\partial \pi}-z}{(\pi)^{2} u^{-1 \prime}\left(R^{C}\right)}<0, \\
\left\{R^{C} u^{-1 \prime}\left(R^{C}\right)\right\} \frac{\partial \alpha^{* * *}}{\partial \pi} & =\frac{R^{C} z}{\pi^{2}}\left(\frac{\pi}{z} \frac{\partial z}{\partial \pi}-1\right)+R\left(\frac{\partial d}{\partial \pi}-\frac{\partial z}{\partial \pi}\right) \\
& =-\frac{\frac{R^{C} z}{\pi^{2}} \frac{\pi}{\beta}}{\xi \int_{\alpha^{*}}^{\alpha^{*}} u^{\prime}\left(\frac{z}{\alpha \pi}\right) f(\alpha) d \alpha}+\frac{\frac{R^{C} z}{\pi \beta}}{\xi \int_{\alpha^{*}}^{\alpha^{* *}} u^{\prime}\left(\frac{z}{\alpha \pi}\right) f(\alpha) d \alpha}=0 .
\end{aligned}
$$

$\bigodot$ The effect of $R^{C}$ on $z_{S}$. Similarly, substituting (A.9), (A.11), (A.13), and (A.15) into (A.17), and rearranging, we get

$$
\begin{aligned}
\Lambda \frac{\partial z_{S}}{\partial R^{C}} & =-\frac{\partial \Psi_{z}}{\partial d} \frac{\partial \Psi_{k}}{\partial R^{C}}+\frac{\partial \Psi_{k}}{\partial d} \frac{\partial \Psi_{z}}{\partial R^{C}} \\
& =\left[\int_{\alpha^{* * *}}^{1} \frac{R}{R^{C} \alpha} u^{\prime \prime}\left(\frac{\frac{R^{C}}{\pi} z+R(d-z)}{R^{C} \alpha}\right) f(\alpha) d \alpha\right] \\
& \times\left[\frac{1}{\left(R^{C}\right)^{2}} \int_{\alpha^{* * *}}^{1} u^{\prime}\left(\frac{\frac{R^{C}}{\pi} z+R(d-z)}{R^{C} \alpha}\right) f(\alpha) d \alpha+\frac{F\left(\alpha^{* * *}\right)-F\left(\alpha^{* *}\right)}{R^{C}}\right]<0 .
\end{aligned}
$$

Since $\Lambda<0$, we have

$$
\frac{\partial z_{S}}{\partial R^{C}}>0 .
$$

In addition, we will make use of the following result.

$$
\frac{R^{C}}{z_{S}} \frac{\partial z_{S}}{\partial R^{C}}=\frac{\int_{\alpha^{* * *}}^{1} u^{\prime}\left(\frac{\frac{R^{C}}{\pi} z+R(d-z)}{R^{C} \alpha}\right) f(\alpha) d \alpha+R^{C}\left[F\left(\alpha^{* * *}\right)-F\left(\alpha^{* *}\right)\right]}{\xi \int_{\alpha^{*}}^{\alpha^{* *}} u^{\prime}\left(\frac{z}{\alpha \pi}\right) f(\alpha) d \alpha}>0 .
$$


$\bigodot$ The effect of $R^{C}$ on $d_{S}$. Similarly, inserting (A.8), (A.10), (A.13), and (A.15) into (A.17), we obtain

$$
\begin{aligned}
\Lambda \frac{\partial d_{S}}{\partial R^{C}} & =\frac{\partial \Psi_{z}}{\partial z} \frac{\partial \Psi_{k}}{\partial R^{C}}-\frac{\partial \Psi_{k}}{\partial z} \frac{\partial \Psi_{z}}{\partial R^{C}} \\
& =\frac{1}{\left(R^{C}\right)^{2}}\left(-1+\frac{R(d-z) \xi}{\frac{R^{C}}{\pi} z+R(d-z)}\right)\left[\int_{\alpha^{*}}^{\alpha^{* *}} \frac{1}{\alpha \pi} u^{\prime \prime}\left(\frac{z}{\alpha \pi}\right) f(\alpha) d \alpha\right]\left[\int_{\alpha^{* * *}}^{1} u^{\prime}\left(\frac{\frac{R^{C}}{\pi} z+R(d-z)}{R^{C} \alpha}\right) f(\alpha) d \alpha\right] \\
& +\frac{1}{\left(R^{C}\right)^{2}} \frac{\xi\left(\frac{R^{C}}{\pi}-R\right)}{\frac{R^{C}}{\pi} z+R(d-z)}\left[\int_{\alpha^{* * *}}^{1} u^{\prime}\left(\frac{\frac{R^{C}}{\pi} z+R(d-z)}{R^{C} \alpha}\right) f(\alpha) d \alpha\right] \\
& +\left[\frac{\xi}{R^{C}} \frac{\frac{R^{C}}{\pi}-R}{\frac{R^{C}}{\pi} z+R(d-z)} \int_{\alpha^{* * *}}^{1} u^{\prime}\left(\frac{\frac{R^{C}}{\pi} z+R(d-z)}{R^{C} \alpha}\right) f(\alpha) d \alpha\right]\left[F\left(\alpha^{* * *}\right)-F\left(\alpha^{* *}\right)\right]>0,
\end{aligned}
$$

if $\xi<1+\frac{R^{C} z}{\pi R(d-z)}$. Since $\Lambda<0$, we have

$$
\frac{\partial d_{S}}{\partial R^{C}}<0
$$

if $\xi$ is not too big. Using the above results, some long but straightforward calculations show that

$$
\begin{aligned}
\frac{\partial k_{S}}{\partial R^{C}} & =\frac{\partial d_{S}}{\partial R^{C}}-\frac{\partial z_{S}}{\partial R^{C}} \\
& =-\frac{\frac{R^{C}}{\pi} z+(1-\xi) R(d-z)}{\xi R R^{C}}-\frac{z \int_{\alpha^{* * *}}^{1} u^{\prime}\left(\frac{\frac{R^{C}}{\pi} z+R(d-z)}{R^{C}}\right) f(\alpha) d \alpha}{\xi R \pi \int_{\alpha^{*}}^{\alpha^{* *}} u^{\prime}\left(\frac{z}{\alpha \pi}\right) f(\alpha) d \alpha}-\frac{\frac{R^{C}}{\pi} z\left\{F\left(\alpha^{* * *}\right)-F\left(\alpha^{* *}\right)\right\}}{\xi R \int_{\alpha^{*}}^{\alpha^{* *}} u^{\prime}\left(\frac{z}{\alpha \pi}\right) f(\alpha) d \alpha}<0 .
\end{aligned}
$$

Further, we have

$$
\begin{aligned}
\frac{\partial \alpha^{*}}{\partial R^{C}} & =\frac{1}{\pi q^{*}} \frac{\partial z}{\partial R^{C}}>0, \\
\frac{\partial \alpha^{* *}}{\partial R^{C}} & =\frac{\frac{\partial z}{\partial R^{C}} u^{-1 \prime}\left(R^{C}\right)-z \frac{\partial u^{-1 \prime}\left(R^{C}\right)}{\partial R^{C}}}{\pi\left[u^{-1 \prime}\left(R^{C}\right)\right]^{2}}>0, \\
\frac{\partial \alpha^{* * *}}{\partial R^{C}} & =\frac{\left\{\frac{R^{C}}{\pi} \frac{\partial z}{\partial R^{C}}+R\left(\frac{\partial d}{\partial R^{C}}-\frac{\partial z}{\partial R^{C}}\right)\right\} R^{C} u^{-1 \prime}\left(R^{C}\right)}{\left[R^{C} u^{-1 \prime}\left(R^{C}\right)\right]^{2}}-\frac{R(d-z) u^{-1 \prime}\left(R^{C}\right)+\left\{\frac{R^{C}}{\pi} z+R(d-z)\right\} R^{C} \frac{\partial u^{-1 \prime}\left(R^{C}\right)}{\partial R^{C}}}{\left[R^{C} u^{-1 \prime}\left(R^{C}\right)\right]^{2}} .
\end{aligned}
$$


Since $\frac{R^{C}}{u^{-1 \prime}\left(R^{C}\right)} \frac{\partial u^{-1 \prime}\left(R^{C}\right)}{\partial R^{C}}=\frac{u^{\prime}\left(u^{-1 \prime}\left(R^{C}\right)\right)}{u^{-1 \prime}\left(R^{C}\right) u^{\prime \prime}\left(u^{-1 \prime}\left(R^{C}\right)\right)}=-\frac{1}{\xi}$, we have

$$
\begin{aligned}
& \left\{R^{C} u^{-1 \prime}\left(R^{C}\right)\right\} \frac{\partial \alpha^{* * *}}{\partial R^{C}}=\frac{R^{C}}{\pi} \frac{\partial z}{\partial R^{C}}+R\left(\frac{\partial d}{\partial R^{C}}-\frac{\partial z}{\partial R^{C}}\right)+\left(\frac{1}{\xi}-1\right) \frac{R(d-z)}{R^{C}}+\frac{z}{\pi \xi}, \\
& =\frac{z}{\pi}\left[\frac{\int_{\alpha^{* * *}}^{1} u^{\prime}\left(\frac{\frac{R^{C}}{\pi} z+R(d-z)}{R^{C} \alpha}\right) f(\alpha) d \alpha}{\xi \int_{\alpha^{*}}^{\alpha^{* *}} u^{\prime}\left(\frac{z}{\alpha \pi}\right) f(\alpha) d \alpha}+\frac{R^{C}\left[F\left(\alpha^{* * *}\right)-F\left(\alpha^{* *}\right)\right]}{\xi \int_{\alpha^{*}}^{\alpha^{* *}} u^{\prime}\left(\frac{z}{\alpha \pi}\right) f(\alpha) d \alpha}+\frac{1}{\xi}\right] \\
& +\left[-\frac{\frac{R^{C}}{\pi} z+(1-\xi) R(d-z)}{\xi R^{C}}-\frac{z \int_{\alpha^{* * *}}^{1} u^{\prime}\left(\frac{\frac{R^{C}}{\pi} z+R(d-z)}{R^{C} \alpha}\right) f(\alpha) d \alpha}{\xi \pi \int_{\alpha^{*}}^{\alpha^{* *}} u^{\prime}\left(\frac{z}{\alpha \pi}\right) f(\alpha) d \alpha}\right. \\
& \left.-\frac{\frac{R^{C}}{\pi} z\left\{F\left(\alpha^{* * *}\right)-F\left(\alpha^{* *}\right)\right\}}{\xi \int_{\alpha^{*}}^{\alpha^{* *}} u^{\prime}\left(\frac{z}{\alpha \pi}\right) f(\alpha) d \alpha}+\frac{R(d-z)(1-\xi)}{\xi R^{C}}\right]=0 .
\end{aligned}
$$

This completes the proof of the corollary.

\section{Proof of Lemma 4}

We have the following system of equations derived from the first order conditions:

$$
\begin{aligned}
u^{\prime}\left(\frac{\theta z}{\alpha \pi}+\frac{b}{\alpha}\right)-1 & =\frac{\mu \pi}{z}, \\
u^{\prime}\left(\frac{\theta z}{\alpha \pi}+\frac{b}{\alpha}\right)-R^{C}\left(\eta+\mu_{z}\right) & =-\mu_{b},
\end{aligned}
$$

where $\mu \geq 0$ is the Lagrange multiplier of $\theta \leq 1, \mu_{b} \geq 0$ is the Lagrange multiplier of the nonnegativity constraint $b \geq 0$, and $\mu_{l} \geq 0$ is the Lagrange multiplier of the borrowing constraint, $R l \geq R^{C} b$.

There are four cases for the solution to the above equations (A.22) and (A.23).

Case 1: $\theta<1$ and $b=0$. Since $\theta<1$ implies $\mu=0$, we have in (A.22),

$$
u^{\prime}\left(\frac{\theta z}{\alpha \pi}+\frac{b}{\alpha}\right)=1
$$

This implies in (A.23) that we must have $\mu_{b}>0$, leading to $b=0$. Note that $b=0$ and $u^{\prime}\left(q^{n}\right)=1$ further lead to

$$
\theta=\frac{\alpha \pi q^{*}}{z}
$$

and $\theta<1 \Longleftrightarrow \alpha<\alpha^{*} \equiv \frac{z}{\pi q^{*}}$. Hence, for $\alpha \in\left(0, \alpha^{*}\right)$, the solution is $\theta<1$ and $b=0$.

Case 2: $\theta=1$ and $b=0 . \theta=1$ and $b=0$ lead to $\mu \geq 0, \mu_{z}=0$ and $\mu_{b} \geq 0$, which yield

$$
\begin{aligned}
& u^{\prime}\left(\frac{z}{\alpha \pi}\right) \geq 1 \quad \Longleftrightarrow \alpha \geq \alpha^{*} \\
& u^{\prime}\left(\frac{z}{\alpha \pi}\right) \leq \eta R^{C} \quad \Longleftrightarrow \alpha \leq \alpha_{\eta}^{* *}
\end{aligned}
$$


where $\alpha_{\eta}^{* *} \equiv \frac{z}{\pi u^{-1 \prime}\left(\eta R^{C}\right)}>\frac{z}{\pi q^{*}} \equiv \alpha^{*}$ with $\eta R^{C}>1$. Hence, for $\alpha \in\left[\alpha^{*}, \alpha_{\eta}^{* *}\right]$, the solution is $\theta=1$ and $b=0$.

Case 3: $\theta=1$ and $b \in\left(0, \frac{R l}{R^{C}}\right) . \quad \mu_{z}=0$ and $\mu_{b}=0$ lead to

$$
u^{\prime}\left(\frac{z}{\pi \alpha}+\frac{b}{\alpha}\right)=\eta R^{C} \Longleftrightarrow b=\alpha u^{-1 \prime}\left(\eta R^{C}\right)-\frac{z}{\pi} .
$$

This implies that $b>0 \Longleftrightarrow \alpha>\alpha_{\eta}^{* *} \equiv \frac{z}{\pi u^{-1 \prime}\left(\eta R^{C}\right)}$ and $R^{C} b<R l \Longleftrightarrow \alpha<\alpha_{\eta}^{* * *} \equiv$ $\frac{R l+\frac{R^{C}}{\pi} z}{R^{C} u^{-1 /}\left(\eta R^{C}\right)}$. Hence, for $\alpha \in\left(\alpha_{\eta}^{* *}, \alpha_{\eta}^{* * *}\right)$, the solution is $\theta=1$ and $b \in\left(0, \frac{R l}{R^{C}}\right)$.

Case 4: $\theta=1$ and $b=\frac{R l}{R^{C}} \cdot \mu_{l} \geq 0$ and $\mu_{b}=0$ lead to $R^{C} b=R l$ and

$$
u^{\prime}\left(\frac{z}{\alpha \pi}+\frac{R l}{\alpha R^{C}}\right) \geq \eta R^{C} \Longleftrightarrow \alpha \geq \alpha_{\eta}^{* * *} \equiv \frac{\frac{R^{C}}{\pi} z+R l}{R^{C} u^{-1 \prime}\left(\eta R^{C}\right)} .
$$

Hence, for $\alpha \in\left[\alpha_{\eta}^{* * *}, 1\right)$, the solution is $\theta=1$ and $b=\frac{R l}{R^{C}}$.

The above covers all the possible cases and completes the proof.

\section{Proof of Proposition 2}

First of all, we shall identify the parameter space in which $l=d-z>0$. In the first order condition,

$$
\Phi(z, d) \equiv \frac{1}{\pi} \Phi_{z}(z, d)-R \Phi_{l}(z, d) \geq 0 \quad(=\text { if } z<d),
$$

where $\Phi_{z}, \Phi_{l}$ are given by (10) and (11), respectively. Observe that

$$
\begin{aligned}
\Phi(0, d) & =\left(\frac{\eta R^{C}}{\pi}-\eta R\right)\left[F\left(\frac{R d}{R^{C} u^{-1 \prime}\left(\eta R^{C}\right)}\right)+\frac{1}{\eta R^{C}} \int_{\frac{R d}{R^{C} u^{-1 /\left(\eta R^{C}\right)}}}^{1} u^{\prime}\left(\frac{R d}{R^{C} \alpha}\right) f(\alpha) d \alpha\right]-\eta R(\lambda-1) \\
& =\frac{1}{\beta}\left[\frac{R^{C}\{1-\eta \beta R(\lambda-1)\}}{\pi R}-1\right] \\
& \equiv \bar{\Phi}\left(R^{C}\right),
\end{aligned}
$$

where the second expression uses the Euler equation (11). Clearly, $\bar{\Phi}\left(R^{C}\right)$ is linear and strictly increasing in $R^{C}$, and $\bar{\Phi}\left(R^{C}\right)=-\eta R(\lambda-1)<0$ as $R^{C} \rightarrow \pi R$. There exists a unique value such that $\bar{\Phi}\left(R^{C}\right)=0$, or

$$
R^{C}=\frac{\pi R}{1-\eta \beta R(\lambda-1)} \equiv \underline{R}^{C} .
$$

Then it follows that $\bar{\Phi}\left(R^{C}\right)<0$ if $R^{C}<\underline{R}^{C}$ and $\bar{\Phi}\left(R^{C}\right)>0$ if $R^{C}>\underline{R}^{C}$. 
Further,

$\pi \frac{\partial \Phi(z, d)}{\partial z}=\int_{\alpha^{*}}^{\alpha_{\eta}^{* *}} \frac{1}{\alpha \pi} u^{\prime \prime}\left(\frac{z}{\alpha \pi}\right) f(\alpha) d \alpha+\left(1-\frac{\pi R}{R^{C}}\right) \int_{\alpha_{\eta}^{* * *}}^{1} \frac{\frac{R^{C}}{\pi}-R}{R^{C} \alpha} u^{\prime \prime}\left(\frac{\frac{R^{C}}{\pi} z+R(d-z)}{R^{C} \alpha}\right) f(\alpha) d \alpha<0$,

and with $d>0$ satisfying (3),

$$
\begin{aligned}
\pi \Phi(d, d) & =F\left(\left.\alpha^{*}\right|_{z=d}\right)+\int_{\left.\alpha^{*}\right|_{z=d}}^{1} u^{\prime}\left(\frac{d}{\pi \alpha}\right) f(\alpha) d \alpha-\pi \eta R\left[F\left(\left.\alpha_{\eta}^{* * *}\right|_{z=d}\right)+\frac{1}{\eta R^{C}} \int_{\left.\alpha_{\eta}^{* * *}\right|_{z=d}}^{1} u^{\prime}\left(\frac{d}{\pi \alpha}\right) f(\alpha) d \alpha+\lambda-1\right] \\
& =\frac{\pi}{\beta}-\pi \eta R\left[F\left(\left.\alpha_{\eta}^{* * *}\right|_{z=d}\right)+\frac{1}{\eta R^{C}} \int_{\left.\alpha_{\eta}^{* * *}\right|_{z=d}}^{1} u^{\prime}\left(\frac{d_{N}}{\pi \alpha}\right) f(\alpha) d \alpha+\lambda-1\right] \\
& \equiv \tilde{\Phi}\left(R^{C}\right) .
\end{aligned}
$$

In the last expression, we have: $\tilde{\Phi}^{\prime}\left(R^{C}\right)>0 ; \tilde{\Phi}\left(R^{C}\right)>0$ for $R^{C} \geq \frac{1}{\eta} u^{\prime}\left(\frac{d_{N}}{\pi}\right)$ leading to $\left.\alpha_{\eta}^{* * *}\right|_{z=d}=\min \left\{\frac{d_{N}}{\pi u^{-1 \prime}\left(\eta R^{C}\right)}, 1\right\}=1$. Since $\Phi(0, d)=0$ at $R^{C}=\underline{R}^{C}$ and $\Phi(z, d)$ is strictly decreasing in $z$, we must have $\tilde{\Phi}\left(\underline{R}^{C}\right)<0$. Thus, there exists a value $\hat{R}^{C *}\left(>\underline{R}^{C}\right)$ such that $\tilde{\Phi}\left(R^{C}\right)=0$. We have $\tilde{\Phi}\left(R^{C}\right)>0$ if $R^{C}>\hat{R}^{C *}$ and $\tilde{\Phi}\left(R^{C}\right)<0$ if $R^{C}<\hat{R}^{C *}$.

We now show the existence and uniqueness of an equilibrium solution $\left(z_{R}, d_{R}\right)>0$ given $R^{C} \in\left(\max \left\{\underline{R}^{C}, 1 / \eta\right\}, \hat{R}^{C *}\right)$.

The solution has to satisfy the following system of equations:

$\Phi_{z}(z, d) \equiv F\left(\alpha^{*}\right)+\int_{\alpha^{*}}^{\alpha_{\eta}^{* *}} u^{\prime}\left(\frac{z}{\alpha \pi}\right) f(\alpha) d \alpha+\left[F\left(\alpha_{\eta}^{* * *}\right)-F\left(\alpha_{\eta}^{* *}\right)\right] \eta R^{C}+\int_{\alpha_{\eta}^{* * *}}^{1} u^{\prime}\left(\frac{\frac{R^{C}}{\pi} z+R(d-z)}{R^{C} \alpha}\right) f(\alpha) d \alpha=\frac{\pi}{\beta}$

$\Phi_{l}(z, d) \equiv \eta F\left(\alpha_{\eta}^{* * *}\right)+\frac{1}{R^{C}} \int_{\alpha_{\eta}^{* * *}}^{1} u^{\prime}\left(\frac{\frac{R^{C}}{\pi} z+R(d-z)}{R^{C} \alpha}\right) f(\alpha) d \alpha+\eta(\lambda-1)=\frac{1}{\beta R}$.

We first examine (A.26). Observe that:

$$
\begin{aligned}
& \frac{\partial \Phi_{z}(z, d)}{\partial z}=\int_{\alpha^{*}}^{\alpha_{\eta}^{* *}} \frac{1}{\alpha \pi} u^{\prime \prime}\left(\frac{z}{\alpha \pi}\right) f(\alpha) d \alpha+\int_{\alpha_{\eta}^{* * *}}^{1} \frac{\frac{R^{C}}{\pi}-R}{R^{C} \alpha} u^{\prime \prime}\left(\frac{\frac{R^{C}}{\pi} z+R(d-z)}{R^{C} \alpha}\right) f(\alpha) d \alpha<0 \\
& \frac{\partial \Phi_{z}(z, d)}{\partial d}=\int_{\alpha_{\eta}^{* * *}}^{1} \frac{R}{R^{C} \alpha} u^{\prime \prime}\left(\frac{\frac{R^{C}}{\pi} z+R(d-z)}{R^{C} \alpha}\right) f(\alpha) d \alpha<0
\end{aligned}
$$

$\Phi_{z}\left(z_{N}, d_{N}\right)=\frac{\pi}{\beta}$ where $d_{N}=z_{N} ; \Phi_{z}\left(\underline{z}_{\eta}, d\right)=\frac{\pi}{\beta}$ for sufficiently high values of $d$ such that $\alpha_{\eta}^{* * *}=\min \left\{\frac{\frac{R^{C}}{\pi} z+R(d-z)}{R^{C} u^{-1 \prime}\left(\eta R^{C}\right)}, 1\right\}=1$ with some lower bound $\underline{z}_{\eta} \in\left(0, z_{N}\right)$. Hence, the implicit equation (A.26) determines a function $z=z_{\eta}(d)$ that satisfies $z_{\eta}^{\prime}(d)<0, z_{\eta}\left(d_{N}\right)=z_{N}$ and $z_{\eta}(d)=\underline{z}_{\eta}>0$ at some $d \in\left(d_{N}, \infty\right)$ that leads to $\alpha_{\eta}^{* * *}=1$. Notice that with $\eta \rightarrow 1$, this curve 
becomes identical to the one with the safe asset, but when $\eta<1$, it gives a lower $z$ with the risky asset than with the safe asset, for any given values of $d>d_{N}$.

Consider next (A.27). Observe also that

$$
\begin{aligned}
& \frac{\partial \Phi_{l}(z, d)}{\partial z}=\frac{1}{R^{C}} \int_{\alpha_{\eta}^{* * *}}^{1} \frac{\frac{R^{C}}{\pi}-R}{R^{C} \alpha} u^{\prime \prime}\left(\frac{\frac{R^{C}}{\pi} z+R(d-z)}{R^{C} \alpha}\right) f(\alpha) d \alpha<0 ; \\
& \frac{\partial \Phi_{l}(z, d)}{\partial d}=\frac{1}{R^{C}} \int_{\alpha_{\eta}^{* *}}^{1} \frac{R}{R^{C} \alpha} u^{\prime \prime}\left(\frac{\frac{R^{C}}{\pi} z+R(d-z)}{R^{C} \alpha}\right) f(\alpha) d \alpha<0 .
\end{aligned}
$$

Further,

$$
\Phi_{l}(d, d)=\eta F\left(\left.\alpha_{\eta}^{* * *}\right|_{z=d}\right)+\frac{1}{R^{C}} \int_{\left.\alpha_{\eta}^{* * *}\right|_{z=d}}^{1} u^{\prime}\left(\frac{d}{\pi \alpha}\right) f(\alpha) d \alpha+\eta(\lambda-1)>\frac{1}{\beta R}
$$

for $R^{C}<\hat{R}^{C *}$ and $d=d_{N}$. Just like in the previous analysis with the safe asset, since $\Phi_{l}(d, d)$ is strictly decreasing in $d>d_{N}$, we have $\Phi_{l}(d, d)=\frac{1}{\beta R}$ (i.e., the condition (A.27) holds true with $z=d$ ) for $R^{C}<\hat{R}^{C *}$ only if $d>d_{N}$. Finally, since $\frac{1}{\beta R}>1$, it is impossible to hold the condition (A.27) for values of $d>d_{N}$ that lead to $\alpha_{\eta}^{* * *}=\min \left\{\frac{R^{C}}{R^{C} u^{-1 \prime}\left(\eta R^{C}\right)}, 1\right\}=1$ and hence to $\Phi_{l}(z, d)=1$. Therefore, we must necessarily have $z=0$ at some upper bound $\bar{d}_{\eta} \in\left(d_{N}, \infty\right)$ and so the condition (A.27) has a solution $(z, d)>0$ only with $d \in\left(d_{N}, \bar{d}_{\eta}\right]$. Hence, the implicit equation (A.27) determines a function $\tilde{z}=\tilde{z}_{\eta}(d)$ that satisfies $\tilde{z}_{\eta}^{\prime}(d)<0, \tilde{z}_{\eta}(d)=d$ at some $d>d_{N}$ and $\tilde{z}_{\eta}\left(\bar{d}_{\eta}\right)=0$.

Finally, combining the above analysis, with some low $d \in\left(d_{N}, \bar{d}_{\eta}\right)$, we have $\tilde{z}_{\eta}(d)=d>$ $z_{\eta}(d)$, while with $d=\bar{d}$, we have $\tilde{z}_{\eta}(\bar{d})=0<z_{\eta}(\bar{d})$. Further,

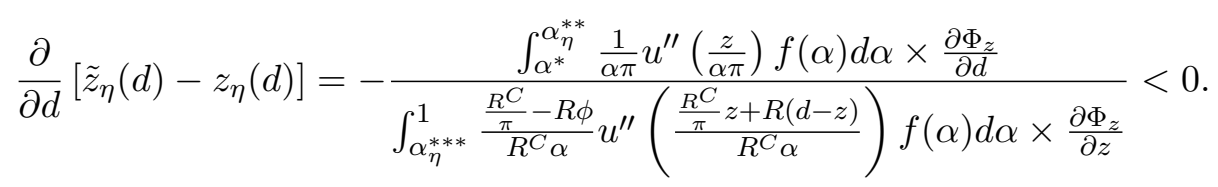

Therefore, the two curves, $z=z_{\eta}(d)$ and $\tilde{z}=\tilde{z}_{\eta}(d)$, must intersect once, at $d \in\left(d_{N}, \bar{d}_{\eta}\right)$ and $z \in\left(\underline{z}_{\eta}, z_{N}\right)$, implying that there exists a unique solution to (A.26) and (A.27).

\section{Proof of Lemma 5}

Part 1 of the Lemma follows from Propositions 1 and 2. Part 2 of the Lemma follows since $-d^{S}+\beta V^{S}\left(d^{S}\right)=-d^{N}+\beta V\left(d^{N}\right)<-d^{R}+\beta V^{R}\left(d^{R}\right)$ for $R^{C} \in\left[R^{C *}, \hat{R}^{C *}\right)$ from Proposition 1 and 2. Similarly, part 3 of the Lemma follows since $-d^{S}+\beta V^{S}\left(d^{S}\right)>-d^{R}+\beta V^{R}\left(d^{R}\right)=$ $-d^{N}+\beta V\left(d^{N}\right)$ for $R^{C} \in\left[\hat{R}^{C *}, R^{C *}\right)$ from Propositions 1 and 2 . 
To prove parts 4 and 5 , it is necessary to derive $\Delta\left(R^{C}, \eta\right)$ as a function of $R^{C}$ and $\eta$. In a stationary monetary equilibrium, the net expected values of depositing in a bank with the safe and risky assets are given by

$$
\begin{aligned}
-d_{S}+\beta V^{s}\left(d_{S}\right) & =-\frac{d_{S}}{1-\beta}+\frac{\beta}{1-\beta}\left[\int_{0}^{\alpha^{*}}\left\{\alpha\left(u\left(q^{*}\right)-q^{*}\right)+\frac{z_{S}}{\pi}\right\} f(\alpha) d \alpha+\int_{\alpha^{*}}^{\alpha^{* *}} \alpha u\left(\frac{z}{\alpha \pi}\right) f(\alpha) d \alpha\right. \\
& +\int_{\alpha^{* *}}^{\alpha^{* * *}}\left\{\alpha u\left(u^{-1 \prime}\left(R^{C}\right)\right)-\left(\alpha u^{-1 \prime}\left(R^{C}\right)-\frac{z_{S}}{\pi}\right)\right\} f(\alpha) d \alpha \\
& +\int_{\alpha^{* * *}}^{1}\left\{\alpha u\left(\frac{\frac{R^{C}}{\pi} z_{S}+R\left(d_{S}-z_{S}\right)}{R^{C} \alpha}\right)-\frac{R}{R^{C}}\left(d_{S}-z_{S}\right)\right\} f(\alpha) d \alpha \\
& \left.+\{1-E(\alpha)\}\left\{u\left(q^{*}\right)-q^{*}\right\}+R\left(d_{S}-z_{S}\right)+\left(1-\frac{1}{\pi}\right) z_{S}\right]
\end{aligned}
$$

and

$$
\begin{aligned}
-d_{R}+\beta V^{r}\left(d_{R}\right) & =-\frac{d_{R}}{1-\beta}+\frac{\beta}{1-\beta}\left[\int_{0}^{\alpha^{*}}\left\{\alpha\left(u\left(q^{*}\right)-q *\right)-\frac{z_{R}}{\pi}\right\} f(\alpha) d \alpha+\int_{\alpha^{*}}^{\alpha_{\eta}^{* *}} \alpha u\left(\frac{z_{R}}{\alpha \pi}\right) f(\alpha) d \alpha\right. \\
& +\int_{\alpha_{\eta}^{* *}}^{\alpha_{\eta}^{* * *}}\left\{\alpha u\left(u^{-1 \prime}\left(\eta R^{C}\right)\right)-\left(\alpha u^{-1 \prime}\left(\eta R^{C}\right)-\frac{z_{R}}{\pi}\right)\right\} f(\alpha) d \alpha \\
& +\int_{\alpha_{\eta}^{* * *}}^{1}\left\{\alpha u\left(\frac{\frac{R^{C}}{\pi} z_{R}+R\left(d_{R}-z_{R}\right)}{R^{C} \alpha}\right)-\frac{R}{R^{C}}\left(d_{R}-z_{R}\right)\right\} f(\alpha) d \alpha \\
& \left.+\{1-E(\alpha)\}\left\{u\left(q^{*}\right)-q^{*}\right\}+\eta \lambda R\left(d_{R}-z_{R}\right)+\left(1-\frac{1}{\pi}\right) z_{R}\right]
\end{aligned}
$$

respectively. Using the two above equations, we have

$$
\begin{aligned}
\Delta\left(R^{C}, \eta\right) & =(1-\beta \eta \lambda R)\left(d_{R}-d_{S}\right)+\beta R(1-\eta \lambda) d_{S}-\beta(R-1) z_{S}+\beta(\eta \lambda R-1) z_{R} \\
& +\beta\left[\int_{\alpha_{\eta}^{*}}^{\alpha^{*}} \alpha\left\{u\left(q^{*}\right)-q^{*}\right\} f(\alpha) d \alpha+\int_{\alpha^{*}}^{\alpha^{* *}} \alpha\left\{u\left(\frac{z_{S}}{\alpha \pi}\right)-\frac{z_{S}}{\alpha \pi}\right\} f(\alpha) d \alpha\right. \\
& +\int_{\alpha^{* *}}^{\alpha^{* * *}} \alpha\left\{u\left(u^{-1 \prime}\left(R^{C}\right)\right)-u^{-1 \prime}\left(R^{C}\right)\right\} f(\alpha) d \alpha \\
& +\int_{\alpha^{* * *}}^{1} \alpha\left\{u\left(\frac{\frac{R^{C}}{\pi} z_{S}+R\left(d_{S}-z_{S}\right)}{R^{C} \alpha}\right)-\frac{\frac{R^{C}}{\pi} z_{S}+R\left(d_{S}-z_{S}\right)}{R^{C} \alpha}\right\} f(\alpha) d \alpha \\
& -\int_{\alpha_{\eta}^{*}}^{\alpha_{\eta}^{* *}} \alpha\left\{u\left(\frac{z_{R}}{\alpha \pi}\right)-\frac{z_{R}}{\alpha \pi}\right\} f(\alpha) d \alpha-\int_{\alpha_{\eta}^{* *}}^{\alpha_{\eta}^{* * *}} \alpha\left\{u\left(u^{-1 \prime}\left(\eta R^{C}\right)\right)-u^{-1 \prime}\left(\eta R^{C}\right)\right\} f(\alpha) d \alpha \\
& \left.-\int_{\alpha_{\eta}^{* * *}}^{1} \alpha\left\{u\left(\frac{\frac{R^{C}}{\pi} z_{R}+R\left(d_{R}-z_{R}\right)}{R^{C} \alpha}\right)-\frac{\frac{R^{C}}{\pi} z_{R}+R\left(d_{R}-z_{R}\right)}{R^{C} \alpha}\right\} f(\alpha) d \alpha\right], \quad \text { (A.28) }
\end{aligned}
$$

where $\alpha_{\eta}^{*} \equiv z_{R} / \pi q^{*} \leq \alpha^{*}=z_{S} / \pi q^{*}$. Since $d_{R} \rightarrow d_{S}$ and $z_{R} \rightarrow z_{S}$ as $\eta \rightarrow 1$ from Proposition 2 , then $\lim _{\eta \rightarrow 1} \Delta\left(R^{C}, \eta\right)=0$, which proves part 4 of the Lemma.

To prove the fifth claim, differentiating $\Delta\left(R^{C}, \eta\right)$ with respect to $R^{C}$ and using the envelop 
theorem imply that

$$
\begin{aligned}
\frac{\partial \Delta}{\partial R^{C}}\left(R^{C}, \eta\right) & =(1-\beta) \beta\left\{\frac{\partial V^{s}\left(d_{S}\right)}{\partial R^{C}}-\frac{\partial V^{r}\left(d_{R}\right)}{\partial R^{C}}\right\} \\
& =\frac{R^{C}-1}{u^{\prime \prime}\left(u^{-1 \prime}\left(R^{C}\right)\right)} \int_{\alpha^{* *}}^{\alpha^{* * *}} \alpha f(\alpha) d \alpha-\frac{R\left(d_{S}-z_{S}\right)}{\left(R^{C}\right)^{2}} \int_{\alpha^{* * *}}^{1}\left\{u^{\prime}\left(\frac{\frac{R^{C}}{\pi} z_{S}+R\left(d_{S}-z_{S}\right)}{R^{C} \alpha}\right)-1\right\} f(\alpha) d \alpha \\
& -\frac{\eta\left(\eta R^{C}-1\right)}{u^{\prime \prime}\left(u^{-1 \prime}\left(\eta R^{C}\right)\right)} \int_{\alpha_{\eta}^{* *}}^{\alpha_{\eta}^{* * *}} \alpha f(\alpha) d \alpha+\frac{R\left(d_{R}-z_{R}\right)}{\left(R^{C}\right)^{2}} \int_{\alpha_{\eta}^{* * *}}^{1}\left\{u^{\prime}\left(\frac{\frac{R^{C}}{\pi} z_{R}+R\left(d_{R}-z_{R}\right)}{R^{C} \alpha}\right)-1\right\} f(\alpha) d \alpha .
\end{aligned}
$$

Since $d_{R} \rightarrow d_{S}$ and $z_{R} \rightarrow z_{S}$ as $\eta \rightarrow 1$, it follows that $\lim _{\eta \rightarrow 1} \frac{\partial \Delta}{\partial R^{C}}\left(R^{C}, \eta\right)=0$.

To prove the final claim, taking the limit as $R^{C} \rightarrow \underline{R}^{C}$ yields $z_{R} \rightarrow 0$ by Proposition 2, which leads to $\alpha_{\eta}^{*} \rightarrow 0, \alpha_{\eta}^{* *} \rightarrow 0, \alpha_{\eta}^{* * *} \rightarrow \frac{R d_{R}}{\underline{R}^{C} u^{-1 \prime}\left(\eta \underline{R}^{C}\right)}$, and

$$
\begin{aligned}
\Delta\left(R^{C}, \eta\right) & \rightarrow(1-\beta \eta \lambda R)\left(d_{R}-d_{S}\right)+\beta R d_{S}(1-\eta \lambda)-\beta(R-1) z_{S} \\
& +\beta\left[\int_{0}^{\alpha^{*}} \alpha\left\{u\left(q^{*}\right)-q^{*}\right\} f(\alpha) d \alpha+\int_{\alpha^{*}}^{\alpha^{* *}} \alpha\left\{u\left(\frac{z_{S}}{\alpha \pi}\right)-\frac{z_{S}}{\alpha \pi}\right\} f(\alpha) d \alpha\right. \\
& +\int_{\alpha^{* *}}^{\alpha^{* * *}} \alpha\left\{u\left(u^{-1 \prime}\left(\underline{R}^{C}\right)\right)-u^{-1 \prime}\left(\underline{R}^{C}\right)\right\} f(\alpha) d \alpha \\
& \left.+\int_{\alpha^{* * *}}^{1} \alpha u\left(\frac{\frac{\underline{R}^{C}}{\pi} z_{S}+R\left(d_{S}-z_{S}\right)}{\underline{R}^{C} \alpha}\right)-\frac{\frac{\underline{R}^{C}}{\pi} z_{S}+R\left(d_{S}-z_{S}\right)}{\underline{R}^{C} \alpha}\right\} f(\alpha) d \alpha \\
& \left.-\int_{0}^{\alpha_{\eta}^{* * *}} \alpha\left\{u\left(u^{-1 \prime}\left(\eta \underline{R}^{C}\right)\right)-u^{-1 \prime}\left(\eta \underline{R}^{C}\right)\right\} f(\alpha) d \alpha-\int_{\alpha_{\eta}^{* * *}}^{1} \alpha\left\{u\left(\frac{R d_{R}}{\underline{R}^{C} \alpha}\right)-\frac{R d_{R}}{\underline{R}^{C} \alpha}\right\} f(\alpha) d \alpha\right]
\end{aligned}
$$

The latter big blanket is negative, and if $\eta \lambda \approx 1$ and $\beta R \approx 1$, the first line of (A.29) becomes $-(1-\beta) z_{S}<0$, leading to $\Delta\left(R^{C}, \eta\right)<0$. This completes all the proofs of Lemma 5 .

\section{Proof of Lemma 6}

Denote the expected return of the risky asset by $R_{E}(\eta) R \equiv \eta \lambda R(\leq R)$. Then, equation (A.25), $\tilde{\Phi}\left(\hat{R}^{C *}\right)=0$, which determines $\hat{R}^{C *}>\underline{R}^{C}$, can be rewritten as

$$
-\eta\left\{1-F\left(\alpha_{\eta}^{* * *}\right)\right\}+\frac{1}{\hat{R}^{C *}} \int_{\alpha_{\eta}^{* * *}}^{1} u^{\prime}\left(\frac{d}{\pi \alpha}\right) f(\alpha) d \alpha+R_{E}(\eta)=\frac{1}{\beta R} .
$$

Note that, in the limit as $\eta \rightarrow 1, \hat{R}^{C *} \rightarrow R^{C *}$ (i.e., the critical value with the risky asset approaches to the one with the safe asset) and $R_{E}(\eta) \rightarrow 1$. For our purpose, we consider a fixed amount of decrease in $\eta$ away from $\eta=1$ to $\eta=1-\epsilon$, with some admissible $\epsilon>0$, and a varying decrease in $R_{E}(\eta)$ away from 1 to $1-\epsilon_{\eta}$, with some arbitrary $\epsilon_{\eta}>0$, and its influence on (A.30). Differentiating the L.H.S. of (A.30) with respect to $\eta$,

$$
-\left\{1-F\left(\alpha_{\eta}^{* * *}\right)\right\}+R_{E}^{\prime}(\eta)
$$


which is negative (positive) when $R_{E}^{\prime}(\eta)>0$ is small (large), that is, when $\epsilon_{\eta}$ is relatively large (small). This implies that given values of $\hat{R}^{C *}$ and $\eta<1$, the L.H.S. of (A.30) is high (low) when $R_{E}(\eta)$ is high (low). Therefore, since the L.H.S. of (A.30) is decreasing in $\hat{R}^{C *}$, there exists a unique critical value denoted by $R_{E}^{*}(\eta)=(\eta \lambda)^{*}<1$ such that $\hat{R}^{C *}>R^{C *}$ if $\eta \lambda>(\eta \lambda)^{*}$ and $\hat{R}^{C *}<R^{C *}$ if $\eta \lambda<(\eta \lambda)^{*}$.

\section{Proof of Proposition 3}

From Lemma 5, if the expected return on the risky asset, $\eta \lambda$, is sufficiently high or close to unity, the set of $\left(R^{C *}, \hat{R}^{C *}\right)$ is nonempty, and the risky asset is selected for $R^{C} \in\left[R^{C *}, \hat{R}^{C *}\right)$. In addition, from Lemma 5 and 6 , since $\lim _{R^{C} \rightarrow R^{C}} \Delta\left(R^{C}, \eta\right)<0, \Delta\left(R^{C *}, \eta\right)<0$, and $\frac{\partial \Delta}{\partial R^{C}}\left(R^{C}, \eta\right) \approx 0$ if $\eta \lambda$ and $\beta R$ are sufficiently high or close to unity, by continuity the risky asset is also selected for $R^{C} \in\left[\underline{R}^{C}, R^{C *}\right)$. Thus, the risky asset is always selected when the bank uses the discount window, that is, when $R^{C} \in\left[\underline{R}^{C}, \hat{R}^{C *}\right)$.

\section{Proof of Proposition 4}

Differentiating (15) with respect to $\kappa$ yields

$$
\begin{array}{r}
\frac{\partial z_{R}^{\kappa}}{\partial \kappa}\left\{\kappa \frac{\partial \Phi_{z}}{\partial z}(\kappa d, d)+(1-\kappa) \pi R \frac{\partial \Phi_{l}}{\partial z}(\kappa d, d)\right\}+\frac{\partial d_{R}^{\kappa}}{\partial \kappa}\left\{\kappa \frac{\partial \Phi_{z}}{\partial d}(\kappa d, d)+(1-\kappa) \pi R \frac{\partial \Phi_{l}}{\partial d}(\kappa d, d)\right\} \\
=\pi R \Phi_{l}(\kappa d, d)-\Phi_{z}(\kappa d, d)>0 . \quad \text { (A.31) }
\end{array}
$$

The last inequality follows from $\Phi\left(\kappa d_{R}^{\kappa}, d_{R}^{\kappa}\right)<0$. Applying $\frac{\partial z_{R}^{\kappa}}{\partial \kappa}=d_{R}^{\kappa}+\kappa \frac{\partial d_{R}^{\kappa}}{\partial \kappa}$ into (A.31) yields

$$
\begin{array}{r}
\frac{\partial d_{R}^{\kappa}}{\partial \kappa}\left[\kappa\left\{\kappa \frac{\partial \Phi_{z}}{\partial z}(\kappa d, d)+(1-\kappa) \pi R \frac{\partial \Phi_{l}}{\partial z}(\kappa d, d)\right\}+\left\{\kappa \frac{\partial \Phi_{z}}{\partial d}(\kappa d, d)+(1-\kappa) \pi R \frac{\partial \Phi_{l}}{\partial d}(\kappa d, d)\right\}\right] \\
=\pi R \Phi_{l}(\kappa d, d)-\Phi_{z}(\kappa d, d)-d_{R}^{\kappa}\left\{\kappa \frac{\partial \Phi_{z}}{\partial z}(\kappa d, d)+(1-\kappa) \pi R \frac{\partial \Phi_{l}}{\partial z}(\kappa d, d)\right\} .
\end{array}
$$

Since $\frac{\partial \Phi_{z}}{\partial z}<0, \frac{\partial \Phi_{z}}{\partial d}<0, \frac{\partial \Phi_{l}}{\partial z}<0$, and $\frac{\partial \Phi_{l}}{\partial d}<0$, we obtain

$$
\frac{\partial d_{R}^{\kappa}}{\partial \kappa}<0
$$

In addition, we have

$$
\begin{aligned}
\frac{\partial z_{R}^{\kappa}}{\partial \kappa} & =d_{R}^{\kappa}+\frac{\kappa\left[\pi R \Phi_{l}-\Phi_{z}-d_{R}^{\kappa}\left\{\kappa \frac{\partial \Phi_{z}}{\partial z}+(1-\kappa) \pi R \frac{\partial \Phi_{l}}{\partial z}\right\}\right]}{\kappa\left\{\kappa \frac{\partial \Phi_{z}}{\partial z}+(1-\kappa) \pi R \frac{\partial \Phi_{l}}{\partial z}\right\}+\left\{\kappa \frac{\partial \Phi_{z}}{\partial d}+(1-\kappa) \pi R \frac{\partial \Phi_{l}}{\partial d}\right\}} \\
& =\frac{d_{R}^{\kappa}\left\{\kappa \frac{\partial \Phi_{z}}{\partial d}+(1-\kappa) \pi R \frac{\partial \Phi_{l}}{\partial d}\right\}+\kappa\left(\pi R \Phi_{l}-\Phi_{z}\right)}{\kappa\left\{\kappa \frac{\partial \Phi_{z}}{\partial z}+(1-\kappa) \pi R \frac{\partial \Phi_{l}}{\partial z}\right\}+\left\{\kappa \frac{\partial \Phi_{z}}{\partial d}+(1-\kappa) \pi R \frac{\partial \Phi_{l}}{\partial d}\right\}}
\end{aligned}
$$


The terms in the denominator are negative. The terms in the numerator can be rewritten as

$$
\begin{aligned}
& d_{R}^{\kappa}\left\{\kappa \frac{\partial \Phi_{z}}{\partial d}+(1-\kappa) \pi R \frac{\partial \Phi_{l}}{\partial d}\right\}+\kappa\left(\pi R \Phi_{l}-\Phi_{z}\right) \\
= & {\left[\kappa\left(\frac{\pi R}{R^{C}}-1\right)-\xi \frac{\pi R}{R^{C}}\right] \int_{\alpha_{\eta}^{* *}}^{1} u^{\prime}\left(\frac{\frac{R^{C}}{\pi} z_{R}^{\kappa}+R\left(d_{R}^{\kappa}-z_{R}^{\kappa}\right)}{R^{C} \alpha}\right) f(\alpha) d \alpha } \\
+ & \kappa \pi R\left[\eta F\left(\alpha_{\eta}^{* * *}\right)+\eta(\lambda-1)\right]-\kappa\left[F\left(\alpha^{*}\right)+\int_{\alpha^{*}}^{\alpha_{\eta}^{* *}} u^{\prime}\left(\frac{z_{R}^{\kappa}}{\alpha \pi}\right)+\left[F\left(\alpha_{\eta}^{* * *}\right)-F\left(\alpha_{\eta}^{* *}\right)\right] \eta R^{C}\right],
\end{aligned}
$$

which is positive if $\xi$ is sufficiently small. Thus, we obtain

$$
\frac{\partial z_{R}^{\kappa}}{\partial \kappa}<0
$$

if $\xi$ is sufficiently small. Otherwise, it is positive. The proposition follows.

\section{Proof of Proposition 5}

The effects of a change in $\rho$ on the optimal values of $z_{S}^{\rho}$ and $d_{S}^{\rho}$ are determined by

$$
\begin{aligned}
\left(\begin{array}{c}
\frac{\partial z_{S}^{\rho}}{\partial \rho} \\
\frac{\partial d_{S}^{\rho}}{\partial \rho}
\end{array}\right) & =\frac{1}{\rho}\left(\begin{array}{cc}
\frac{\partial \Psi_{z}}{\partial z}+\frac{1-\rho}{\rho} \Upsilon^{\prime}(z) & \frac{\partial \Psi_{z}}{\partial d} \\
\frac{\partial \Psi_{k}}{\partial z} & \frac{\partial \Psi_{k}}{\partial d}
\end{array}\right)^{-1}\left(\begin{array}{c}
\Upsilon(z)-\Psi_{z}(z, d) \\
1-\Psi_{k}(z, d)
\end{array}\right) \\
& =\frac{1}{\rho \Lambda_{\rho}}\left(\begin{array}{cc}
\frac{\partial \Psi_{k}}{\partial d} & -\frac{\partial \Psi_{z}}{\partial d} \\
-\frac{\partial \Psi_{k}}{\partial z} & \frac{\partial \Psi_{z}}{\partial z}+\frac{1-\rho}{\rho} \Upsilon^{\prime}(z)
\end{array}\right)\left(\begin{array}{c}
\Upsilon(z)-\Psi_{z}(z, d) \\
1-\Psi_{k}(z, d)
\end{array}\right)
\end{aligned}
$$

where

$$
\begin{aligned}
\Lambda_{\rho} & \equiv \operatorname{det}\left(\begin{array}{cc}
\frac{\partial \Psi_{z}}{\partial z}+\frac{1-\rho}{\rho} \Upsilon^{\prime}(z) & \frac{\partial \Psi_{z}}{\partial d} \\
\frac{\partial \Psi_{k}}{\partial z} & \frac{\partial \Psi_{k}}{\partial d}
\end{array}\right) \\
& =-\left(\frac{\partial \Psi_{z}}{\partial d} \frac{\partial \Psi_{k}}{\partial z}-\frac{\partial \Psi_{z}}{\partial z} \frac{\partial \Psi_{k}}{\partial d}\right)+\frac{1-\rho}{\rho} \Upsilon^{\prime}(z) \frac{\partial \Psi_{k}}{\partial d}>0
\end{aligned}
$$

The last inequality follows since $\Upsilon^{\prime}(z)<0, \frac{\partial \Psi_{k}}{\partial d}<0$ and $\Lambda \equiv\left(\frac{\partial \Psi_{z}}{\partial d} \frac{\partial \Psi_{k}}{\partial z}-\frac{\partial \Psi_{z}}{\partial z} \frac{\partial \Psi_{k}}{\partial d}\right)<0$ (see the proof of Corollary 3).

$\bigodot$ The effect of $\rho$ on $z_{S}^{\rho}$. From (A.34), using (16) and (17) we obtain

$$
\begin{aligned}
\rho \Lambda_{\rho} \frac{\partial z_{S}^{\rho}}{\partial \rho} & =\frac{\partial \Psi_{k}}{\partial d}\left\{\Upsilon\left(z_{S}^{\rho}\right)-\Psi_{z}\left(z_{S}^{\rho}, d_{S}^{\rho}\right)\right\}-\frac{\partial \Psi_{z}}{\partial d}\left\{1-\Psi_{k}\left(z_{S}^{\rho}, d_{S}^{\rho}\right)\right\} \\
& =\frac{1}{\rho}\left[\frac{\partial \Psi_{k}}{\partial d}\left\{\Upsilon\left(z_{S}^{\rho}\right)-\frac{\pi}{\beta}\right\}+\frac{\partial \Psi_{z}}{\partial d}\left(\frac{1}{\beta R}-1\right)\right]<0 .
\end{aligned}
$$

The last inequality follows since $\frac{\partial \Psi_{k}}{\partial d}<0, \frac{\partial \Psi_{z}}{\partial d}<0$, and $\Upsilon\left(z_{S}^{\rho}\right)>\Upsilon\left(z_{N}\right)=\frac{\pi}{\beta}$. 
$\bigodot$ The effect of $\rho$ on $d_{S}^{\rho}$. Similarly, from (A.34), we obtain

$$
\begin{aligned}
\rho \Lambda_{\rho} \frac{\partial d_{S}^{\rho}}{\partial \rho} & =-\frac{\partial \Psi_{k}}{\partial z}\left\{\Upsilon\left(z_{S}^{\rho}\right)-\Psi_{z}\left(z_{S}^{\rho}, d_{S}^{\rho}\right)\right\}+\left\{\frac{\partial \Psi_{z}}{\partial z}+\frac{1-\rho}{\rho} \Upsilon^{\prime}\left(z_{S}^{\rho}\right)\right\}\left\{1-\Psi_{k}\left(z_{S}^{\rho}, d_{S}^{\rho}\right)\right\} \\
& =-\frac{1}{\rho}\left[\frac{\partial \Psi_{k}}{\partial z}\left\{\Upsilon\left(z_{S}^{\rho}\right)-\frac{\pi}{\beta}\right\}+\left\{\frac{\partial \Psi_{z}}{\partial z}+\frac{1-\rho}{\rho} \Upsilon^{\prime}\left(z_{S}^{\rho}\right)\right\}\left(\frac{1}{\beta R}-1\right)\right]>0,
\end{aligned}
$$

since $\frac{\partial \Psi_{k}}{\partial z}<0, \frac{\partial \Psi_{z}}{\partial z}<0$, and $\Upsilon^{\prime}\left(z_{S}^{\rho}\right)<0$. The proposition follows. 


\section{References}

[1] Acharya, V. V., Gromb, D., \& Yorulmazer, T. (2012). Imperfect competition in the interbank market for liquidity as a rationale for central banking. American Economic Journal: Macroeconomics, 4(2), 184-217.

[2] Allen, F. \& Gale, D. (1998). Optimal financial crises. Journal of Finance, 53(4), 12451284.

[3] Allen, F., Carletti, E., \& Gale, D. (2009). Interbank market liquidity and central bank intervention. Journal of Monetary Economics, 56(5), 639-652.

[4] Andolfatto, D., Berentsen, A., \& Martin, F. M. (2017). Money, Banking and Financial Markets. Federal Reserve Bank of St. Louis Working Paper Series, (2017-023).

[5] Antinolfi, G., Huybens, E., \& Keister, T. (2001). Monetary stability and liquidity crises: The role of the lender of last resort. Journal of Economic Theory, 99(1-2), 187-219.

[6] Antinolfi, G., \& Keister, T. (2006). Discount window policy, banking crises, and indeterminacy of equilibrium. Macroeconomic Dynamics, 10(1), 1-19.

[7] Bagehot, W. (1873). Lombard Street: A description of the money market. Scribner, Armstrong \& Company.

[8] Bencivenga, V. R., \& Camera, G. (2011). Banking in a matching model of money and capital. Journal of Money, Credit and Banking, 43(s2), 449-476.

[9] Berentsen, A., Camera, G., \& Waller, C. (2007). Money, credit and banking. Journal of Economic theory, 135(1), 171-195.

[10] Bordo, M. (1990). The lender of last resort: alternative views and historical experience. Economic Review, (Jan), 18-29.

[11] Bordo, M. D. (2014). Rules for a lender of last resort: An historical perspective. Journal of Economic Dynamics and Control, 49, 126-134.

[12] Calomiris, C. W., \& Gorton, G. (1991). The origins of banking panics: models, facts, and bank regulation. In Financial markets and financial crises (pp. 109-174). University of Chicago Press.

[13] Champ, B., Smith, B. D., \& Williamson, S. D. (1996). Currency elasticity and banking panics: Theory and evidence. Canadian Journal of Economics, 828-864. 
[14] Cooper, R., \& Ross, T. W. (1998). Bank runs: Liquidity costs and investment distortions. Journal of Monetary Economics, 41(1), 27-38.

[15] Cooper, R., \& Ross, T. W. (2002). Bank runs: Deposit insurance and capital requirements. International Economic Review, 43(1), 55-72.

[16] Corrigan, E. G. (1990). Statement before US senate committee on banking. housing and urban affairs, Washington D.C.

[17] Demirgüç-Kunt, A., \& Detragiache, E. (1998). The determinants of banking crises in developing and developed countries. Staff Papers, 45(1), 81-109.

[18] Demirgüç-Kunt, A., \& Detragiache, E. (2005). Cross-country empirical studies of systemic bank distress: a survey. National Institute Economic Review, 192(1), 68-83.

[19] Diamond, D. W., \& Dybvig, P. H. (1983). Bank runs, deposit insurance, and liquidity. Journal of Political Economy, 91(3), 401-419.

[20] Ennis, H. M., \& Keister, T. (2009). Bank runs and institutions: The perils of intervention. American Economic Review, 99(4), 1588-1607.

[21] Ferraris, L., \& Watanabe, M. (2008). Collateral secured loans in a monetary economy. Journal of Economic Theory, 143(1), 405-424.

[22] Ferraris, L., \& Watanabe, M. (2011). Collateral fluctuations in a monetary economy. Journal of Economic Theory, 146(5), 1915-1940.

[23] Fischer, S. (1999). On the need for an international lender of last resort. Journal of Economic Perspectives, 13(4), 85-104.

[24] Flannery, M. J. (1996). Financial crises, payment system problems, and discount window lending. Journal of Money, Credit and Banking, 28(4), 804-824.

[25] Freixas, X., Giannini, C., Hoggarth, G., \& Soussa, F. (2000). Lender of last resort: What have we learned since Bagehot?. Journal of Financial Services Research, 18(1), 63-84.

[26] Freixas, X., \& Jorge, J. (2008). The role of interbank markets in monetary policy: A model with rationing. Journal of Money, Credit and Banking, 40(6), 1151-1176.

[27] Freixas, X., Parigi, B. M., \& Rochet, J. C. (2000). Systemic risk, interbank relations, and liquidity provision by the central bank. Journal of Money, Credit and Banking, 611-638.

[28] Giannini, C. (1999). Enemy of none but a common friend of all? An international perspective on the lender-of-last-resort function. International Monetary Fund. 
[29] Goodfriend, M. \& R. King (1988). Financial Deregulation, Monetary Policy and Central Banking." In Restructuring Banking and Financial Services in America, edited by Williams Haraf and Rose Marie Kushmeider. AEI Studies, 481, Lanham, MD.

[30] Goodhart, C. A. (1987). Why do banks need a central bank?. Oxford Economic Papers, 39(1), 75-89.

[31] Goodhart, C. A. E. (1999). Myths about the lender of last resort. International Finance, $2(3), 339-360$.

[32] Gu, C., Mattesini, F., Monnet, C., \& Wright, R. (2012). Banking: A new monetarist approach. Review of Economic Studies, rds037.

[33] Heider, F., Hoerova, M., \& Holthausen, C. (2015). Liquidity hoarding and interbank market rates: The role of counterparty risk. Journal of Financial Economics, 118(2), 336-354.

[34] Hellmann, T. F., Murdock, K. C., \& Stiglitz, J. E. (2000). Liberalization, moral hazard in banking, and prudential regulation: Are capital requirements enough?. American economic review, 147-165.

[35] Kaufman, George (1991). Lender of last resort: A contemporary perspective. Journal of Financial Services Research, 5, 95-110.

[36] Kydland, F. E., \& Prescott, E. C. (1977). Rules rather than discretion: The inconsistency of optimal plans. Journal of Political Economy, 85(3), 473-491.

[37] Lagos, R., \& Wright, R. (2005). A unified framework for monetary theory and policy analysis. Journal of Political Economy, 113(3), 463-484.

[38] Martin, A. (2006). Liquidity provision vs. deposit insurance: preventing bank panics without moral hazard. Economic Theory, 28, 197-211.

[39] Martin, A. (2009). Reconciling Bagehot and the Fed's response to September 11. Journal of Money, Credit and Banking, 41(2- 3), 397-415.

[40] Matsuoka, T. (2012). Imperfect interbank markets and the lender of last resort. Journal of Economic Dynamics and Control, 36(11), 1673-1687.

[41] Matsuoka, T., \& Watanabe, M. (2017). Banking Panics and Liquidity in a Monetary Economy. TI Discussion Paper Series, 17(091/VII).

[42] Repullo, R. (2004). Capital requirements, market power, and risk-taking in banking. Journal of Financial Intermediation, 13(2), 156-182. 
[43] Repullo, R. (2005) Liquidity, risk taking, and the lender of last resort. International Journal of Central Banking 1,47-80.

[44] Rochet, J. C., \& Vives, X. (2004). Coordination failures and the lender of last resort: Was Bagehot right after all?. Journal of the European Economic Association, 2(6), 1116-1147.

[45] Rocheteau, G., \& Wright, R. (2005). Money in search equilibrium, in competitive equilibrium, and in competitive search equilibrium. Econometrica, 73(1), 175-202.

[46] Smith, B. D. (2002). Monetary policy, banking crises, and the Friedman rule. American Economic Review, 92(2), 128-134.

[47] Solow, R. M. (1982). On the lender of last resort. Financial crises: Theory, history and policy, Cambridge University Press, Cambridge.

[48] Schwartz, A. J. (1992). The misuse of the Fed's discount window. Federal Reserve Bank of St. Louis Review, 74(5), 58-69.

[49] Schwartz, A. J. (2002). Earmarks of a lender of last resort. Financial Crises, Contagion, and the Lender of Last Resort. A Reader. Oxford University Press, Oxford, 2002, 449-460.

[50] Thornton, Henry. (1802) An enquiry into the nature and effects of the paper credit of Great Britain. New York: Augustus M. Kelley. (Reprinted in 1962)

[51] Williamson, S. D. (2012). Liquidity, monetary policy, and the financial crisis: A New Monetarist approach. American Economic Review, 102(6), 2570-2605.

[52] Williamson, S. D. (2016). Scarce collateral, the term premium, and quantitative easing. Journal of Economic Theory, 164, 136-165.

[53] Williamson, S.D. and Wright, R. (2010). New monetarist economics: Models, Handbook of Monetary Economics, vol. 2, Benjamin M. Friedman and Michael Woodford, eds. NorthHolland.

[54] Yokoyama, K. (2018). Bailout by the Bank of Japan in response to the panic of 1927: Lenders and borrowers in the call market. The Society of Economics Nagoya City University Discussion Papers in Economics No. 622. 